4

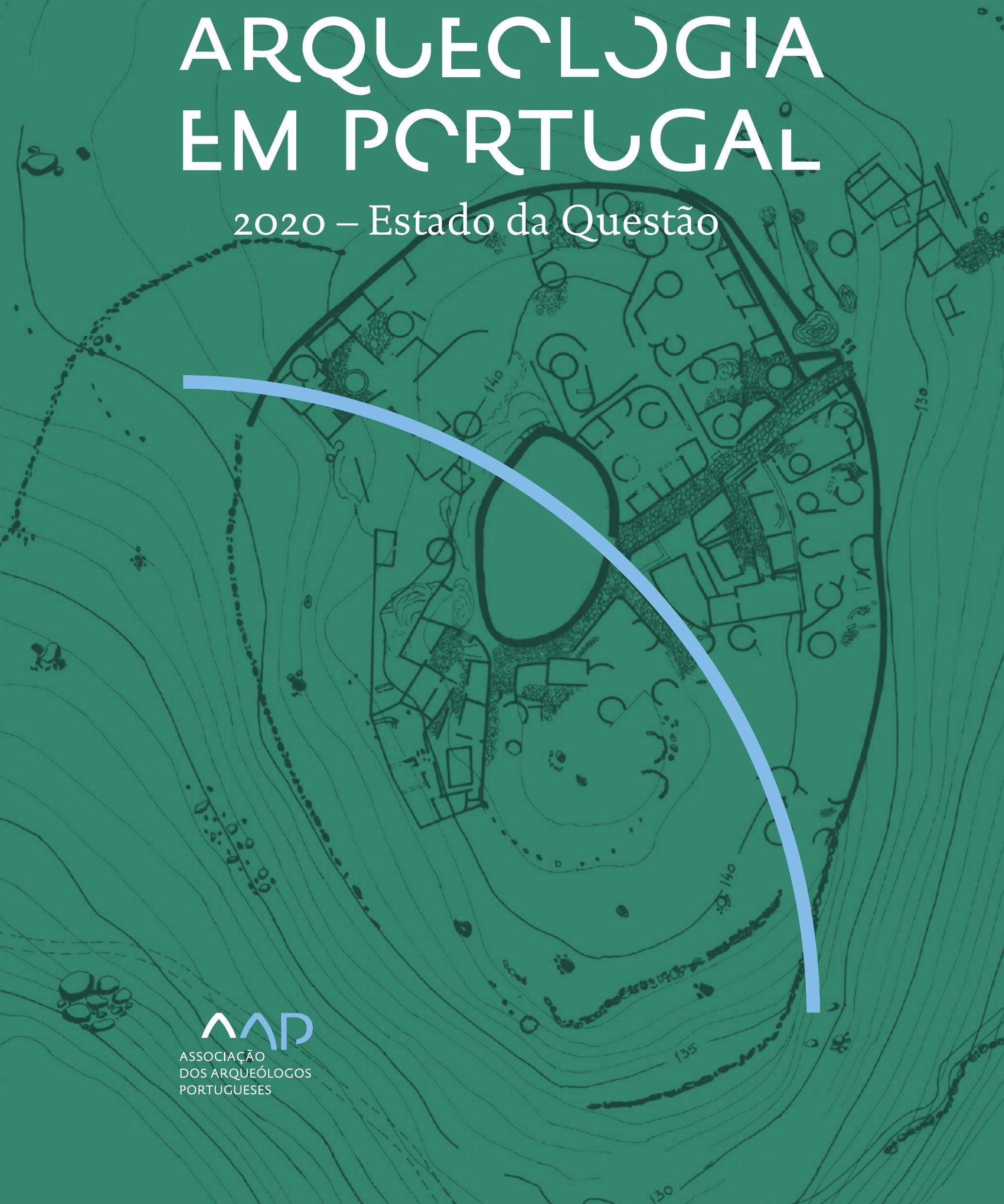


Coordenação editorial: José Morais Arnaud, César Neves e Andrea Martins Design gráfico: Flatland Design

AAP - ISBN: 978-972-9451-89-8

CITCEM - ISBN: 978-989-8970-25-1

Associação dos Arqueólogos Portugueses e CITCEM

Lisboa, 2020

O conteúdo dos artigos é da inteira responsabilidade dos autores. Sendo assim a Associação dos Arqueólogos Portugueses declina qualquer responsabilidade por eventuais equívocos ou questões de ordem ética e legal.

Desenho de capa:

Planta do castro de Monte Mozinho (Museu Municipal de Penafiel).

\section{$\hat{\wedge} \mathrm{P}$}

DOS ARQUEÓLOGOS PORTUGUESES

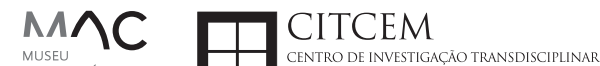
MUSEU
ARQUELLÓGICO
DO CARMO
U.PORTO

FLUP FACULDADE DE LETRAS
UNIVERSIDADE DO PORTO

Apoio

EC para a Ciência 


\section{Índice}

15 Prefácio

José Morais Arnaud

\section{Historiografia e Teoria}

17 Território, comunidade, memória e emoção: a contribuição da história da arqueologia (algumas primeiras e breves reflexões)

Ana Cristina Martins

25 Como descolonizar a arqueologia portuguesa?

Rui Gomes Coelho

41 Arqueologia e Modernidade: uma revisitação pessoal e breve de alguns aspetos da obra homónima de Julian Thomas de 2004

Vítor Oliveira Jorge

57 Dados para a História das Mulheres na Arqueologia portuguesa, dos finais do século XIX aos inícios do século XX: números, nomes e tabelas

Filipa Dimas / Mariana Diniz

73 Retractos da arqueologia portuguesa na imprensa: (in)visibilidades no feminino

Catarina Costeira / Elsa Luís

85 Arqueologia e Arqueólogos no Norte de Portugal Jacinta Bugalhão

101 Vieira Guimarães (1864-1939) e a arqueologia em Tomar: uma abordagem sobre o território e as gentes

João Amendoeira Peixoto / Ana Cristina Martins

115 Os memoráveis? A arqueologia algarvia na imprensa nacional e regional na presente centúria (2001-2019): características, visões do(s) passado(s) e a arqueologia

enquanto marca

Frederico Agosto / João Silva

129 A Evolução da Arqueologia Urbana e a Valorização Patrimonial no Barlavento Algarvio: Os casos de Portimão e Silves

Artur Mateus / Diogo Varandas / Rafael Boavida

\section{Gestão, Valorização e Salvaguarda do Património}

145 O Caderno Reivindicativo e as condições de trabalho em Arqueologia Miguel Rocha / Liliana Matias Carvalho / Regis Barbosa / Mauro Correia / Sara Simões / Jacinta Bugalhão / Sara Brito / Liliana Veríssimo Carvalho / Richard Peace / Pedro Peça / Cézer Santos

155 Os Estudos de Impacte Patrimonial como elemento para uma estratégia sustentável de minimização de impactes no âmbito de reconversões agrícolas Tiago do Pereiro

165 Salvaguarda de Património arqueológico em operações florestais: gestão e sensibilização Filipa Bragança / Gertrudes Zambujo / Sandra Lourenço / Belém Paiva / Carlos Banha / Frederico Tatá Regala / Helena Moura / Jacinta Bugalhão / João Marques / José Correia / Pedro Faria / Samuel Melro

179 Os valores do Património: uma investigação sobre os Sítios Pré-históricos de Arte Rupestre do Vale do Rio Côa e de Siega Verde José Paulo Francisco 
189 Conjugando recursos arqueológicos e naturais para potenciar as visitas ao Geoparque Litoral de Viana do Castelo (Noroeste de Portugal)

Hugo A. Sampaio / Ana M.S. Bettencourt / Susana Marinho / Ricardo Carvalhido

203 Áreas de Potencial Arqueológico na Região do Médio Tejo: Modelo Espacial Preditivo Rita Ferreira Anastácio / Ana Filipa Martins / Luiz Oosterbeek

223 Património Arqueológico e Gestão Territorial: O contributo da Arqueologia para a revisão do PDM de Avis

Ana Cristina Ribeiro

237 A coleção arqueológica do extinto Museu Municipal do Porto - Origens, Percursos e Estudos

Sónia Couto

251 Valpaços - uma nova carta arqueológica

Pedro Pereira / Maria de Fátima Casares Machado

263 Arqueologia na Cidade de Peniche

Adriano Constantino / Luís Rendeiro

273 Arqueologia Urbana: a cidade de Lagos como caso de Estudo Cátia Neto

285 Estratégias de promoção do património cultural subaquático nos Açores. O caso da ilha do Faial

José Luís Neto / José Bettencourt / Luís Borges / Pedro Parreira

297 Carta Arqueológica da Cidade Velha: Uma primeira abordagem

Jaylson Monteiro / Nireide Tavares / Sara da Veiga / Claudino Ramos / Edson Brito /

Carlos Carvalho / Francisco Moreira / Adalberto Tavares

311 Antropologia Virtual: novas metodologias para a análise morfológica e funcional Ricardo Miguel Godinho / Célia Gonçalves

\section{Didáctica da Arqueologia}

327 Como os projetos de Arqueologia podem contribuir para uma comunidade culturalmente mais consciente Alexandra Figueiredo / Claúdio Monteiro / Adolfo Silveira / Ricardo Lopes

337 Educação Patrimonial - Um cidadão esclarecido é um cidadão ativo! Ana Paula Almeida

351 A aproximação da Arqueologia à sala de aula: um caso de estudo no $3^{\circ}$ ciclo do Ensino Básico Luís Serrão Gil

363 Arqueologia 3.o - Pensar e comunicar a Arqueologia para um futuro sustentável Mónica Rolo

377 “Conversa de Arqueólogos" - Divulgar a Arqueologia em tempos de Pandemia Diogo Teixeira Dias

389 Escola Profissional de Arqueologia: desafios e oportunidades Susana Nunes / Dulcineia Pinto / Júlia Silva / Ana Mascarenhas

399 Os Museus de Arqueologia e os Jovens: a oferta educativa para o público adolescente Beatriz Correia Barata / Leonor Medeiros

411 O museu universitário como mediador entre a ciência e a sociedade: o exemplo da secção de arqueologia no Museu de História Natural e da Ciência da Universidade do Porto (MHNC-UP)

Rita Gaspar 
421 Museu de Lanifícios: Real Fábrica de Panos. Atividades no âmbito da Arqueologia Beatriz Correia Barata / Rita Salvado

427 Arqueologia Pública e o caso da localidade da Mata (Torres Novas) Cláudia Manso / Ana Rita Ferreira / Cristiana Ferreira / Vanessa Cardoso Antunes

431 Do sítio arqueológico ao museu: um percurso (também) didático Lídia Fernandes

447 Estão todos convidados para a Festa! E para dançar também... O projecto do Serviço Educativo do Museu Arqueológico do Carmo na $5^{\underline{a}}$ Edição da Festa da Arqueologia Rita Pires dos Santos

459 O “Clã de Carenque”, um projeto didático de arqueologia Eduardo Gonzalez Rocha

469 Mediação cultural: peixe que puxa carroça nas Ruínas Romanas de Troia Inês Vaz Pinto / Ana Patrícia Magalhães / Patrícia Brum / Filipa Santos

481 Didática Arqueológica, experiências do Projeto Mértola Vila Museu Maria de Fátima Palma / Clara Rodrigues / Susana Gómez / Lígia Rafael

\section{Arte Rupestre}

497 Os inventários de arte rupestre em Portugal Mila Simões de Abreu

513 O projeto FIRST-ART - conservação, documentação e gestão das primeiras manifestações de arte rupestre no Sudoeste da Península Ibérica: as grutas do Escoural e Maltravieso Sara Garcês / Hipólito Collado / José Julio García Arranz / Luiz Oosterbeek / António Carlos Silva / Pierluigi Rosina / Hugo Gomes / Anabela Borralheiro Pereira / George Nash / Esmeralda Gomes / Nelson Almeida / Carlos Carpetudo

523 Trabalhos de documentação de arte paleolítica realizados no âmbito do projeto PalæoCôa André Tomás Santos / António Fernando Barbosa / Luís Luís / Marcelo Silvestre / Thierry Aubry

537 Imagens fantasmagóricas, silhuetas elusivas: as figuras humanas na arte do Paleolítico Superior da região do Côa Mário Reis

$55^{1}$ Os motivos zoomórficos representados nas placas de tear de Vila Nova de São Pedro (Azambuja, Portugal) Andrea Martins / César Neves / José M. Arnaud / Mariana Diniz

571 Arte Rupestre do Monte de Góios (Lanhelas, Caminha). Síntese dos resultados dos trabalhos efectuados em 2007-2009 Mário Varela Gomes

599 Gravuras rupestres de barquiformes no Monte de S. Romão, Guimarães, Noroeste de Portugal Daniela Cardoso

613 Círculos segmentados gravados na Bacia do Rio Lima (Noroeste de Portugal): contributos para o seu estudo Diogo Marinho / Ana M.S. Bettencourt / Hugo Aluai Sampaio

631 Equídeos gravados no curso inferior do Rio Mouro, Monção (NW Portugal). Análise preliminar Coutinho, L.M. / Bettencourt, A.M.S / Sampaio, Hugo A.S

645 Paletas na Arte Rupestre do Noroeste de Portugal. Inventário preliminar Bruna Sousa Afonso / Ana M. S. Bettencourt / Hugo A. Sampaio 


\section{Pré-História}

661 O projeto Miño/Minho: balanço de quatro anos de trabalhos arqueológicos Sérgio Monteiro-Rodrigues / João Pedro Cunha-Ribeiro / Eduardo Méndez-Quintas / Carlos Ferreira / Pedro Xavier / José Meireles / Alberto Gomes / Manuel Santonja / Alfredo Pérez-González

677 A ocupação paleolítica da margem esquerda do Baixo Minho: a indústria lítica do sítio de Pedreiras 2 (Monção, Portugal) e a sua integração no contexto regional Carlos Ferreira / João Pedro Cunha-Ribeiro / Sérgio Monteiro-Rodrigues / Eduardo Méndez-Quintas / Pedro Xavier / José Meireles / Alberto Gomes / Manuel Santonja / Alfredo Pérez-González

693 O sítio acheulense do Plistocénico médio da Gruta da Aroeira Joan Daura / Montserrat Sanz / Filipa Rodrigues / Pedro Souto / João Zilhão

703 As sociedades neandertais no Barlavento algarvio: modelos preditivos com recurso aos SIG

Daniela Maio

715 A utilização de quartzo durante o Paleolítico Superior no território dos vales dos rios Vouga e Côa

Cristina Gameiro / Thierry Aubry / Bárbara Costa / Sérgio Gomes / Luís Luís / Carmen Manzano / André Tomás Santos

733 Uma perspetiva diacrónica da ocupação do concheiro do Cabeço da Amoreira (Muge, Portugal) a partir da tecnologia lítica Joana Belmiro / João Cascalheira / Célia Gonçalves

745 Novos dados sobre a Pré-história Antiga no concelho de Palmela. A intervenção arqueológica no sítio do Poceirão I

Michelle Teixeira Santos

757 Problemas em torno de Datas Absolutas Pré-Históricas no Norte do Alentejo Jorge de Oliveira

771 Povoamento pré-histórico nas áreas montanhosas do NO de Portugal: o Abrigo 1 de Vale de Cerdeira Pedro Xavier / José Meireles / Carlos Alves

783 Apreciação do povoamento do Neolítico Inicial na Baixa Bacia do Douro. A Lavra I (Serra da Aboboreira) como caso de estudo Maria de Jesus Sanches

797 O Processo de Neolitização na Plataforma do Mondego: os dados do Sector C do Outeiro dos Castelos de Beijós (Carregal do Sal)

João Carlos de Senna-Martinez / José Manuel Quintã Ventura / Andreia Carvalho / Cíntia Maurício

823 Novos trabalhos na Lapa da Bugalheira (Almonda, Torres Novas) Filipa Rodrigues / Pedro Souto / Artur Ferreira / Alexandre Varanda / Luís Gomes / Helena Gomes / João Zilhão

837 A pedra polida e afeiçoada do sítio do Neolítico médio da Moita do Ourives (Benavente, Portugal)

César Neves

857 Casal do Outeiro (Encarnação, Mafra): novos contributos para o conhecimento do povoamento do Neolítico final na Península de Lisboa.

Cátia Delicado / Carlos Maneira e Costa / Marta Miranda / Ana Catarina Sousa

873 Stresse infantil, morbilidade e mortalidade no sítio arqueológico do Neolítico Final/ Calcolítico ( $4^{\circ}$ e $3^{\circ}$ milénio a.C.) do Monte do Carrascal 2 (Ferreira do Alentejo, Beja) Liliana Matias de Carvalho / Sofia N. Wasterlain 
885 Come together: O Conjunto Megalítico das Motas (Monção, Viana do Castelo) e as expressões Campaniformes do Alto Minho Ana Catarina Basílio / Rui Ramos

899 Trabalhos arqueológicos no sítio Calcolítico da Pedreira do Poio Carla Magalhães / João Muralha / Mário Reis / António Batarda Fernandes

913 O sítio arqueológico de Castanheiro do Vento. Da arquitectura do sítio à arquitectura de um território João Muralha Cardoso

925 Estudo zooarqueológico das faunas do Calcolítico final de Vila Nova de São Pedro (Azambuja, Portugal): Campanhas de 2017 e 2018 Cleia Detry / Ana Catarina Francisco / Mariana Diniz / Andrea Martins / César Neves / José Morais Arnaud

943 As faunas depositadas no Museu Arqueológico do Carmo provenientes de Vila Nova de São Pedro (Azambuja): as campanhas de 1937 a 1967 Ana Catarina Francisco / Cleia Detry / César Neves / Andrea Martins / Mariana Diniz / José Morais Arnaud

959 Análise funcional de material lítico em sílex do castro de Vila Nova de S. Pedro (Azambuja, Portugal): uma primeira abordagem Rafael Lima

971 O recinto da Folha do Ouro 1 (Serpa) no contexto dos recintos de fossos calcolíticos alentejanos

António Carlos Valera / Tiago do Pereiro / Pedro Valério / António M. Monge Soares

\section{Proto-História}

987 Produção de sal marinho na Idade do Bronze do noroeste Português. Alguns dados para uma reflexão

Ana M. S. Bettencourt / Sara Luz / Nuno Oliveira / Pedro P. Simões / Maria Isabel C. Alves / Emílio Abad-Vidal

1001 A estátua-menir do Pedrão ou de São Bartolomeu do Mar (Esposende, noroeste de Portugal) no contexto arqueológico da fachada costeira de entre os rios Neiva e Cávado Ana M. S. Bettencourt / Manuel Santos-Estévez / Pedro Pimenta Simões / Luís Gonçalves

1015 O Castro do Muro (Vandoma/Baltar, Paredes) - notas para uma biografia de ocupação da Idade do Bronze à Idade Média

Maria Antónia D. Silva / Ana M. S. Bettencourt / António Manuel S. P. Silva / Natália Félix

1031 Do Bronze Final à Idade Média - continuidades e hiatos na ocupação de Povoados em Oliveira de Azeméis João Tiago Tavares / Adriaan de Man

1041 As faunas do final da Idade do Bronze no Sul de Portugal: leituras desde o Outeiro do Circo (Beja)

Nelson J. Almeida / Íris Dias / Cleia Detry / Eduardo Porfírio / Miguel Serra

1055 A Espada do Monte das Oliveiras (Serpa) - uma arma do Bronze Pleno do Sudoeste Rui M. G. Monge Soares / Pedro Valério / Mariana Nabais / António M. Monge Soares

1065 São Julião da Branca (Albergaria-a-Velha) - Investigação e valorização de um povoado do Bronze Final

António Manuel S. P. Silva / Paulo A. P. Lemos / Sara Almeida e Silva / Edite Martins de Sá

1083 Do castro de S. João ao Mosteiro de Santa Clara: notícia de uma intervenção arqueológica, em Vila do Conde Rui Pinheiro 
1095 O castro de Ovil (Espinho), um quarto de século de investigação - resultados e questões em aberto

Jorge Fernando Salvador / António Manuel S. P. Silva

1111 O Castro de Salreu (Estarreja), um povoado proto-histórico no litoral do Entre Douro e Vouga

Sara Almeida e Silva / António Manuel S. P. Silva / Paulo A. P. Lemos / Edite Martins de Sá

1127 Castro de Nossa Senhora das Necessidades (Sernancelhe): uma primeira análise artefactual Telma Susana O. Ribeiro

${ }_{1141}$ A cividade de Bagunte. O estado atual da investigação Pedro Brochado de Almeida

1153 Zoomorfos na cerâmica da Idade do Ferro no NW Peninsular: inventário, cronologias e significado Nuno Oliveira / Cristina Seoane

1163 Vasos gregos em Portugal: diferentes maneiras de contar a história do intercâmbio cultural na Idade do Ferro

Daniela Ferreira

1175 Os exotica da necrópole da Idade do Ferro do Olival do Senhor dos Mártires (Alcácer do Sal) no seu contexto regional

Francisco B. Gomes

\section{Antiguidade Clássica e Tardia}

1191 O uso de madeira como combustível no sítio da Quinta de Crestelos (Baixo Sabor): da Idade do Ferro à Romanização Filipe Vaz / João Tereso / Sérgio Simões Pereira / José Sastre / Javier Larrazabal Galarza / Susana Cosme / José António Pereira / Israel Espi

1207 Cultivos de Época Romana no Baixo Sabor: continuidade em tempos de mudança? João Pedro Tereso / Sérgio Simões Pereira / Filipe Santos / Luís Seabra / Filipe Vaz

1221 A casa romana na Hispânia: aplicação dos modelos itálicos nas províncias ibéricas Fernanda Magalhães / Diego Machado / Manuela Martins

1235 As pinturas murais romanas da Rua General Sousa Machado, n. ${ }^{5}$ 1, Chaves José Carvalho

1243 Trás do Castelo (Vale de Mir, Pegarinhos, Alijó) - Uma exploração agrícola romana do Douro

Tony Silvino / Pedro Pereira

1255 A sequência de ocupação no quadrante sudeste de Bracara Augusta: as transformações de uma unidade doméstica Lara Fernandes / Manuela Martins

1263 Os Mosaicos com decoração geométrica e geométrico-vegetalista dos sítios arqueológicos da área do Conuentus Bracaraugustanus. Novas abordagens quanto à conservação, restauro, decoração e datação Maria de Fátima Abraços / Licínia Wrench

1277 “Casa Romana” do Castro de São Domingos (Cristelos, Lousada): Escavação, Estudo e Musealização Paulo André de P. Lemos

1291 A arqueobotânica no Castro de Guifões (Matosinhos, Noroeste de Portugal): O primeiro estudo carpológico

Luís Seabra / Andreia Arezes / Catarina Magalhães / José Varela / João Pedro Tereso 
1305 Um Horreum Augustano na Foz do Douro (Monte do Castelo de Gaia, Vila Nova de Gaia) Rui Ramos

1311 Ponderais romanos na Lusitânia: padrões, formas, materiais e contextos de utilização Diego Barrios Rodríguez

1323 Um almofariz centro-itálico na foz do Mondego

Marco Penajoia

1335 Estruturas romanas de Carnide - Lisboa Luísa Batalha / Mário Monteiro / Guilherme Cardoso

1347 O contexto funerário do sector da "necrópole NO" da Rua das Portas de S. Antão (Lisboa): o espaço, os artefactos, os indivíduos e a sua interconectividade na interpretação do passado Sílvia Loja, José Carlos Quaresma, Nelson Cabaço, Marina Lourenço, Sílvia Casimiro, Rodrigo Banha da Silva, Francisca Alves-Cardoso

${ }_{1361}$ Povoamento em época Romana na Amadora - resultados de um projeto pluridisciplinar Gisela Encarnação / Vanessa Dias

1371 A Arquitectura Residencial em Mirobriga (Santiago do Cacém): contributo a partir de um estudo de caso Filipe Sousa / Catarina Felício

${ }_{1385}$ O fim do ciclo. Saneamento e gestão de resíduos nos edifícios termais de Mirobriga (Santiago do Cacém)

Catarina Felício / Filipe Sousa

1399 Balsa, Topografia e Urbanismo de uma Cidade Portuária Vítor Silva Dias / João Pedro Bernardes / Celso Candeias / Cristina Tété Garcia

1413 No Largo das Mouras Velhas em Faro (2017): novas evidências da necrópole norte de Ossonoba e da sua ocupação medieval Ricardo Costeira da Silva / Paulo Botelho / Fernando Santos / Liliana Nunes

1429 Instrumentos de pesca recuperados numa fábrica de salga em Ossonoba (Faro) Inês Rasteiro / Ricardo Costeira da Silva / Paulo Botelho

1439 A Necrópole Romana do Eirô, Duas Igrejas (Penafiel): intervenção arqueológica de 2016 Laura Sousa / Teresa Soeiro

1457 Ritual, descarte ou afetividade? A presença de Canis lupus familiaris na Necrópole Noroeste de Olisipo (Lisboa)

Beatriz Calapez Santos / Sofia Simões Pereira / Rodrigo Banha da Silva / Sílvia Casimiro / Cleia Detry / Francisca Alves Cardoso

1467 Dinâmicas económicas em Bracara na Antiguidade Tardia Diego Machado / Manuela Martins / Fernanda Magalhães / Natália Botica

1479 Cerâmicas e Vidros da Antiguidade Tardia do Edifício sob a Igreja do Bom Jesus (Vila Nova de Gaia) Joaquim Filipe Ramos

1493 Novos contributos para a topografia histórica de Mértola no período romano e na Antiguidade Tardia Virgílio Lopes

\section{8. Época Medieval}

1511 Cerâmicas islâmicas no Garb setentrional "português": algumas evidências e incógnitas Constança dos Santos / Helena Catarino / Susana Gómez / Maria José Gonçalves / Isabel Inácio / Gonçalo Lopes / Jacinta Bugalhão / Sandra Cavaco / Jaquelina Covaneiro / Isabel Cristina Fernandes / Ana Sofia Gomes 
1525 Contributo para o conhecimento da cosmética islâmica, em Silves, durante a Idade Média Rosa Varela Gomes

1537 Yábura e o seu território - uma análise histórico-arqueológica de Évora entre os séculos VIII-XII José Rui Santos

1547 A encosta sul do Castelo de Palmela - resultados preliminares da escavação arqueológica Luís Filipe Pereira / Michelle Teixeira Santos

1559 A igreja de São Lourenço (Mouraria, Lisboa): um conjunto de silos e de cerâmica medieval islâmica

Andreia Filipa Moreira Rodrigues

1571 O registo material de movimentações populacionais no Médio Tejo, durante os séculos XII-XIII. Dois casos de "sunken featured buildings", nos concelhos de Cartaxo e Torres Novas Marco Liberato / Helena Santos / Nuno Santos

1585 O nordeste transmontano nos alvores da Idade média. Notas para reflexão Ana Maria da Costa Oliveira

1601 Sepulturas escavadas na rocha do Norte de Portugal e do Vale do Douro: primeiros resultados do Projecto SER-NPVD

Mário Jorge Barroca / César Guedes / Andreia Arezes / Ana Maria Oliveira

1619 "Portucalem Castrum Novum" entre o Mediterrâneo e o Atlântico: o estudo dos materiais cerâmicos alto-medievais do arqueossítio da rua de D. Hugo, nํ. 5 (Porto) João Luís Veloso

1627 A Alta Idade Média na fronteira de Lafões: notas preliminares sobre a Arqueologia no Concelho de Vouzela

Manuel Luís Real / Catarina Tente

1641 Um conjunto cerâmico medieval fora de portas: um breve testemunho aveirense Susana Temudo

${ }_{1651}$ Os Lóios do Porto: uma perspetiva integrada no panorama funerário da Baixa Idade Média à Época Moderna em meios urbanos em Portugal

Ana Lema Seabra

1659 O Caminho Português Interior de Santiago como eixo viário na Idade Média Pedro Azevedo

1665 Morfologia Urbana: Um exercício em torno do Castelo de Ourém André Donas-Botto / Jaqueline Pereira

1677 Intervenção arqueológica na Rua Marquês de Pombal/Largo do Espírito Santo (Bucelas, Loures)

Florbela Estêvão / Nathalie Antunes-Ferreira / Dário Ramos Neves / Inês Lisboa

1691 O Cemitério Medieval do Poço do Borratém e a espacialidade funerária na cidade de Lisboa Inês Belém / Vanessa Filipe / Vasco Noronha Vieira / Sónia Ferro / Rodrigo Banha da Silva

1705 Um Espaço Funerário Conventual do séc. XV em Lisboa: o caso do Convento de São Domingos da Cidade Sérgio Pedroso / Sílvia Casimiro / Rodrigo Banha da Silva / Francisca Alves Cardoso

\section{9. Época Moderna e Contemporânea}

1721 Arqueologia Moderna em Portugal: algumas reflexões críticas em torno da quantificação de conjuntos cerâmicos e suas inferências históricas e antropológicas Rodrigo Banha da Silva / André Bargão / Sara da Cruz Ferreira

1733 Faianças de dois contextos entre os finais do século XVI e XVIII do Palácio dos Condes de Penafiel, Lisboa

Martim Lopes / Tomás Mesquita 
1747 Um perfil de consumo do século XVIII na foz do Tejo: O caso do Mercado da Ribeira, Lisboa Sara da Cruz Ferreira / Rodrigo Banha da Silva / André Bargão

1761 Os Cachimbos dos Séculos XVII e XVIII do Palácio Mesquitela e Convento dos Inglesinhos (Lisboa)

Inês Simão / Marina Pinto / João Pimenta / Sara da Cruz Ferreira / André Bargão / Rodrigo Banha da Silva

1775 "Tomar os fumos da erua que chamão em Portugal erua sancta». Estudo de Cachimbos provenientes da Rua do Terreiro do Trigo, Lisboa

Miguel Martins de Sousa / José Pedro Henriques / Vanessa Galiza Filipe

1787 Cachimbos de Barro Caulínitico da Sé da Cidade Velha (República de Cabo Verde)

Rodrigo Banha da Silva / João Pimenta / Clementino Amaro

1801 Algumas considerações sobre espólio não cerâmico recuperado no Largo de Jesus (Lisboa) Carlos Boavida

1815 Adereços de vidro, dos séculos XVI-XVIII, procedentes do antigo Convento de Santana de Lisboa (anéis, braceletes e contas)

Joana Gonçalves / Rosa Varela Gomes / Mário Varela Gomes

1837 Da ostentação, luxo e poder à simplicidade do uso quotidiano: arqueologia e simbologia de joias e adornos da Idade Moderna Portuguesa Jéssica Iglésias

1849 Os amuletos em Portugal - dos objetos às superstições: o coral vermelho Alexandra Vieira

1865 Cerâmicas de Vila Franca de Xira nos séculos XV e XVI Eva Pires

1879 «Não passa por teu o que me pertence». Marcas de individualização associadas a faianças do Convento de Nossa Senhora de Aracoeli, Alcácer do Sal Catarina Parreira / Íris Fragoso / Miguel Martins de Sousa

1891 Cerâmica de Leiria: alguns focos de produção

Jaqueline Pereira / André Donas-Botto

1901 Os Fornos na Rua da Biquinha, em Óbidos Hugo Silva / Filipe Oliveira

1909 A casa de Pêro Fernandes, contador dos contos de D. Manuel I: o sítio arqueológico da Silha do Alferes, Seixal (século XVI) Mariana Nunes Ferreira

1921 O Alto da Vigia (Sintra) e a vigilância e defesa da costa Alexandre Gonçalves / Sandra Santos

1937 O contexto da torre sineira da Igreja de Santa Maria de Loures Paulo Calaveira / Martim Lopes

1949 A Necrópole do Hospital Militar do Castelo de São Jorge e as práticas funerárias na Lisboa de Época Moderna Susana Henriques / Liliana Matias de Carvalho / Ana Amarante / Sofia N. Wasterlain

1963 SAND - Sarilhos Grandes Entre dois Mundos: o adro da Igreja e a Paleobiologia dos ossos humanos recuperados

Paula Alves Pereira / Roger Lee Jesus / Bruno M. Magalhães

1975 Expansão urbana da vila de Cascais no século XVII e XVIII: a intervenção arqueológica na Rua da Vitória no 15 a 17

Tiago Pereira / Vanessa Filipe

1987 Novos dados para o conhecimento do Urbanismo de Faro em época Moderna Ana Rosa 
1995 Um exemplo de Arqueologia Urbana em Alcoutim: o Antigo Edifício dos CTT Marco Fernandes / Marta Dias / Alexandra Gradim / Virgílio Lopes / Susana Gómez Martínez

2007 Palácio dos Ferrazes (Rua das Flores/Rua da Vitória, Porto): a cocheira de Domingos Oliveira Maia

Francisco Raimundo

2021 As muitas vidas de um edifício urbano: História, Arqueologia e Antropologia no antigo Recreatório Paroquial de Penafiel Helena Bernardo / Jorge Sampaio / Marta Borges

2035 O convento de Nossa Senhora da Esperança de Ponta Delgada: o contributo da arqueologia para o conhecimento de um monumento identitário João Gonçalves Araújo / N’Zinga Oliveira

2047 Arqueologia na ilha do Corvo... em busca da capela de Nossa Senhora do Rosário Tânia Manuel Casimiro / José Luís Neto / Luís Borges / Pedro Parreira

2059 Perdidos à vista da Costa. Trabalhos arqueológicos subaquáticos na Barra do Tejo Jorge Freire / José Bettencourt / Augusto Salgado

2071 Arqueologia marítima em Cabo Verde: enquadramento e primeiros resultados do projecto CONCHA

José Bettencourt / Adilson Dias / Carlos Lima / Christelle Chouzenoux / Cristóvão Fonseca / Dúnia Pereira / Gonçalo Lopes / Inês Coelho / Jaylson Monteiro / José Lima / Maria Eugénia Alves / Patrícia Carvalho / Tiago Silva

2085 Trabalhos arqueológicos na Cidade Velha (Ribeira Grande de Santiago, Cabo Verde): reflexões sobre um projecto de investigação e divulgação patrimonial André Teixeira / Jaylson Monteiro / Mariana Mateus / Nireide Tavares / Cristovão Fonseca / Gonçalo C. Lopes / Joana Bento Torres / Dúnia Pereira / André Bargão / Aurélie Mayer / Bruno Zélie / Carlos Lima / Christelle Chouzenoux / Inês Henriques / Inês Pinto Coelho / José Lima / Patrícia Carvalho / Tiago Silva

2103 A antiga fortificação de Quelba / Khor Kalba (E.A.U.). Resultados de quatro campanhas de escavações, problemáticas e perspectivas futuras Rui Carita / Rosa Varela Gomes / Mário Varela Gomes / Kamyar Kamyad

2123 Colónias para homens novos: arqueologia da colonização agrária fascista no noroeste ibérico Xurxo Ayán Vila / José Mạ . Señorán Martín 


\title{
SAND - SARILHOS GRANDES ENTRE DOIS MUNDOS: O ADRO DA IGREJA E A PALEOBIOLOGIA DOS OSSOS HUMANOS RECUPERADOS
}

\author{
Paula Alves Pereira ${ }^{1}$, Roger Lee Jesus ${ }^{2}$, Bruno M. Magalhães ${ }^{3}$
}

\begin{abstract}
RESUMO
A escavação arqueológica de salvaguarda realizada em 2008 no Largo da Igreja de Sarilhos Grandes originou um projeto de investigação interdisciplinar que visa o estudo da sua população desde época Medieval. Este trabalho pretende discutir a análise paleobiológica da coleção osteológica humana escavada em 2008. Foi estimado um número mínimo de 24 indivíduos entre o total de 21 enterramentos mal preservados, 5 ossários e restantes ossos desarticulados. De entre as lesões identificadas (e.g., cáries, tártaro, osteomas, nódulo de Schmorl, osteoartrose), várias parecem indiciar deficiências nutricionais, principalmente nos indivíduos mais jovens. Uma nova intervenção arqueológica está já programada para o local de forma a serem aprofundadas várias questões e abertas novas perspetivas sobre a população de Sarilhos Grandes.
\end{abstract}

Palavras-chave: Arqueologia, Necrópole, Paleodemografia, Paleopatologia, Stresse nutricional.

\begin{abstract}
The archaeological excavation carried out in 2008 at the Largo da Igreja of Sarilhos Grandes triggered an interdisciplinary research project aiming to study its population since the medieval period. This work aims to discuss the paleobiological analysis of the human osteological remains excavated in 2008. A minimum number of 24 individuals were estimated out of 21 poorly preserved skeletons, five ossuaries and other disarticulated bones. Several pathologies were identified (e.g., caries, calculus, osteomas, Schmorl nodules, osteoarthrosis) with special focus on lesions possibly associated with nutritional stress in younger individuals. A new archaeological excavation is programmed aiming to better understand several issues and open new perspectives about the population of Sarilhos Grandes.
\end{abstract}

Keywords: Archaeology, Churchyard, Palaeodemography, Palaeopathology, Nutritional stress.

\section{O PROJETO “SAND - SARILHOS GRANDES ENTRE DOIS MUNDOS"}

O projeto SAND incide na zona especial de proteção da Ermida de Nossa Senhora da Piedade e Igreja de S. Jorge, classificados como imóveis de Interesse Público pelo Decreto $n^{\circ} 45 / 93$, DR, r. ${ }^{\circ}$ série-B, n. ${ }^{\circ} 280$ de 30 novembro 1993. O monumento localiza-se no Largo da Igreja da freguesia de Sarilhos Grandes, concelho do Montijo, distrito de Setúbal (Figura 1). A génese do projeto recua à intervenção arqueológica de 2008 onde foram recolhidas amostras de solo dos enterramentos escavados com vista à sua pesquisa paleoparasitológica, isto é, o estudo de parasitas associados ao material osteológico humano recuperado. As amostras foram analisadas no laboratório

\footnotetext{
1. Coordenadora do projeto; paulalvespereira@gmail.com

2. Historiador. Bolseiro do projeto de investigação "SAND”. CHAM - Centro de Humanidades (FCSH, Universidade NOVA de Lisboa); CHSC (UC); rogerlee.pj@gmail.com

3. Bioantropólogo. Bolseiro do projeto de investigação "SAND”. CIAS - Centro de Investigação em Antropologia e Saúde; Departamento de Ciências da Vida, Universidade de Coimbra; bruno.miguel.silva.magalhaes@gmail.com
} 
da Fundação FioCruz, no Rio de Janeiro. As análises, concluídas em 2015, revelaram, para além de ovos de Ascaris lumbricoides, vulgarmente conhecida como lombriga, cuja ocorrência é relativamente comum em populações humanas pelo contacto com fezes ou pela ingestão de água ou alimentos contaminados, ovos de Oxyuroidea, provavelmente adquiridos pelo consumo de carne de caça, e do género Trichostrongylus, relacionado com animais domésticos como coelhos, porcos, ovinos e bovinos, parasitas pela primeira vez reportados em populações históricas europeias (Pereira $\&$ alii, 2017; Sianto $\&$ alii, 2018). As pesquisas aos conteúdos intestinais mostraram, igualmente, vestígios diversos dos quais se salientam alimentos como o arroz, moluscos e amido de batata. Estes dados, associados a algumas das cronologias, obtidas por radiocarbono, conferem grande importância a este pequeno grupo de indivíduos e a Sarilhos Grandes. O conhecimento atual indica que a batata (Solanum tuberosum) terá sido trazida da América para as Ilhas Canárias em 1567 (Lobo-Cabrera, 1988), desconhecendo-se a data de chegada a Portugal. As questões alimentares levantadas continuaram a ser exploradas por análise de isótopos que evidenciaram uma alimentação variada, com consumo de proteínas de origem animal, vegetal e marinha (peixe de rio e de mar e moluscos), como seria expectável pela localização geográfica de Sarilhos Grandes. Mais recentemente, iniciou-se o estudo do tártaro dentário cujas primeiras análises levaram à identificação de conídios do fungo Candida albicans, cuja presença na cavidade oral potencia o surgimento de cáries (Pereira \& alii, 2017).

\subsection{Enquadramento Histórico}

A freguesia de Sarilhos Grandes situa-se no actual concelho do Montijo e encontra-se ligada administrativamente a esse centro urbano desde tempos medievais. A referência documental mais antiga ao lugar data de 1251, numa sentença relativa aos dízimos arrecadados pela Sé de Lisboa nos territórios na banda d'além do Tejo. Já desde esse século que todas as terras da Península de Setúbal e das suas proximidades estavam sob jurisdição da Ordem de Santiago, uma das mais importantes ordens militares em território português. Com um desenvolvimento modesto ao longo dos séculos, Sarilhos obteve autorização do bispo de Lisboa, D. João Anes, em 1390, para a construção de uma nova igreja, dependente da igreja de S. Maria de Sabonha, então sede de um concelho que abrangia os actuais territórios do Montijo (então Aldeia Galega do Ribatejo) e Alcochete (Dias, 2005).

Já nos inícios do século XVI a igreja de S. Jorge ganhou uma capela adjacente, colada ao corpo do templo, mas com acesso pelo exterior, dedicada ao culto de Nossa Senhora da Piedade. Era uma capela privativa, da responsabilidade do Dr. João Cotrim, um dos mais importantes desembargadores do reinado de D. Manuel I, envolvido na própria reorganização administrativa dos forais. O seu cunhado, Rui de Castanheda, fora um dos capitães da segunda armada de Vasco da Gama à Ásia, em 1502, e tinha também vastas propriedades em Sarilhos Grandes. Estas acabariam por ser herdadas pelo seu sobrinho, Rui Cotrim de Castanheda (filho do mencionado Dr. João Cotrim), fidalgo da Casa Real cujo túmulo se encontra devidamente assinalado na ermida da Virgem da Piedade.

Paralelamente a esta pequena fidalguia radicada em Sarilhos, a terra foi crescendo nesse século, à sombra das suas salinas, dos moinhos de maré e dos seus frondosos pinhais. De uma população de c. 130 habitantes em 1532 passa para quase 200 em 1620, iniciando então um paulatino decréscimo populacional assinalado em múltiplas fontes do século XVIII e que se prolongaria até finais do XIX, quando o lugar voltaria a ganhar destaque no contexto da crescente industrialização de Lisboa e da sua área metropolitana. O objetivo do presente trabalho é apresentar e discutir a análise paleobiológica da coleção osteológica humana proveniente da escavação de 2008.

\section{MATERIAL E MÉTODOS}

Neste trabalho são estudados os 21 esqueletos, 5 ossários e restantes ossos desarticulados escavados em 2008 durante a intervenção arqueológica no adro da igreja matriz de S. Jorge de Sarilhos Grandes (concelho do Montijo).

O primeiro passo consistiu na limpeza a seco de todos os ossos e dentes, seguido da sua marcação. Posteriormente, foi avaliada a preservação dos esqueletos através do método proposto por Bello \& alii (2006), tendo sido calculado o Índice de Preservação Anatómica (IPA), o Índice de Representatividade Óssea (IRO) e o Índice de Qualidade Óssea (IQO). Para a análise paleodemográfica foram analisados o número mínimo de indivíduos (NMI), a diagnose sexual e a estimativa da idade à morte. Para a análi- 
se do NMI foi utilizado o método desenvolvido por Herrmann (1990 in Silva, 1993) para os ossos longos do esqueleto pós-craniano e o método sugerido por Ubelaker (1974), para os restantes tipos de peças ósseas completas e fragmentadas. A observação do tipo de dentição (decidual, mista ou definitiva), do tamanho dos ossos e da presença e/ou fusão das epífises permitiu a separação dos vestígios osteológicos humanos em não adultos ou adultos. A categoria etária determinou a escolha dos métodos para avaliação do perfil biológico dos indivíduos. Assim, para a diagnose sexual foram aplicados os métodos sugeridos por Ferembach $\&$ alii (1980) e por Buikstra e Ubelaker (1994) para o esqueleto axial e de Cardoso (2000), Wasterlain (2000) e Silva (1995) para o esqueleto apendicular. No que diz respeito à idade à morte, para os não adultos foram usadas as estimativas osteométricas referidas por Carneiro (2016) e Scheurer e Black (200o), para além das de AlQahtani, Hector e Liversidge (2010) para os dentes; para os adultos foram usadas as metodologias referidas por MacLaughlin (1990) para a clavícula e por Iscan e Loth (1993) e de DiGangi \& alii (2009), para as costelas.

Todos os ossos foram analisados macroscopicamente e para o dignóstico diferencial foram seguidas as recomendações gerais dos manuais de Ortner (2003) e Aufderheide e Rodríguez-Martín (2011) e, especificamente para não adultos, de Lewis (2018). As cáries foram registadas segundo o método desenvolvido por Hillson (2001) e o tártaro através do método de Buikstra e Ubelaker (1994). A osteoartrose foi registada segundo as indicações de Rogers e Waldron (1995) através de classificação binária, como presente ou ausente, quando a superfície articular é afetada por eburnação ou por porosidade e labiação.

Todos os dados foram inventariados no software microsoft Excel 2010 e analisados estatisticamente com o Statistical Package for the Social Sciences (SPSS), versão 21.0.

\subsection{A preservação dos esqueletos e as dificulda- des na análise osteológica}

Os 21 esqueletos encontram-se em muito mau estado de preservação. Mostram um índice de representatividade óssea (IRO) geral de $44,7 \%$, o que significa que a maioria dos ossos ou partes anatómicas se encontra ausente (Figura 2). Para além disso, enquadram-se também nas piores classes de preservação (classes 1, 2 e 3), quer no Índice de Preserva- ção Anatómica (IPA), quer no Índice de Qualidade Óssea (IQO).

$\mathrm{Na}$ realidade, a preservação dos esqueletos limitou sobremaneira a restante análise paleobiológica e vários terão sido os agentes tafonómicos, principalmente extrínsecos ao próprio osso, que contribuíram para a degradação. Se nos detivermos nos fatores especificamente observados aquando da escavação (a que, de resto, nos iremos limitar neste trabalho), a ausência de 55,3\% de ossos ou partes anatómicas dos esqueletos parece estar associada à pouca profundidade dos enterramentos, uma vez que apenas um não tinha sido perturbado pela construção de infra-estruturas mais recentes (Pereira $\mathbb{\&}$ alii, 2008). A reutilização contínua do espaço funerário terá também tido importância (Pereira \& alii, 2008), tal como é compreensível e descrito em outros cemitérios no país com utilização intensiva ao longo de centenas de anos.

O ambiente extremamente húmido das areias onde os indivíduos foram inumados (a Formação Pliocénica de Santa Marta) e a que estiveram sujeitos durante séculos parece ter sido outro fator relevante para a deficiente preservação. Isto terá contribuido para que muitos dos ossos, apesar de mais ou menos 'completos' e in situ, fragmentassem ou, em último caso, se desfizessem depois de recolhidos, mesmo com o maior dos cuidados. Foi o que aconteceu, por exemplo, com quase todos os ossos dos indivíduos 1, 2, 3, 4 ou 5, aspecto que é, no entanto, comum a outros esqueletos. A literatura mostra-nos que a inumação em solos arenosos húmidos pode acelerar a perda de estabilidade óssea (e.g., Carter e Tibbett, 2008), sendo que o processo de degradação principal de material orgânico no solo aeróbico e húmido está associado à oxidação biológica através do ecossistema presente e que geralmente resulta na sua destruição (Kibblewhite, Tóth e Hermann, 2015).

\subsection{Avaliação do perfil biológico e paleodemogra- fia: a população de Sarilhos Grandes proveniente do adro da igreja de $\mathrm{S}$. Jorge}

Foi estimado um número mínimo de 24 indivíduos entre o total de 21 enterramentos, 5 ossários e restantes ossos desarticulados escavados no adro da igreja matriz de Sarilhos Grandes. O número mínimo foi conseguido através do fémur direito, o osso mais representado entre todos os restos osteológicos humanos recuperados. Foi seguida uma abordagem conservadora em que os fémures direitos 
desarticulados poderiam pertencer aos indivíduos inumados, desde que dentro da mesma faixa etária. Foram identificados 7 indivíduos não adultos $(3$ fetos/recém-nascidos e 4 enquadráveis na $1^{\underline{a}}$ infância [até 6 anos]), 12 adultos (10 >2O anos, 1 adulto jovem [20-29 anos] e 1 adulto maduro [ $>29$ anos]) e 2 de idade indeterminada.

Dada a presença de bastantes indivíduos não adultos (para os quais a aplicação de métodos para o sexo biológico é bastante mais difícil que nos adultos) e a má preservação dos ossos recuperados, a avaliação no terreno (Pereira \& alii, 2008) e em laboratório apenas permitiu identificar 3 indivíduos de sexo feminino e 3 de sexo masculino, sendo os restantes $15(71,4 \%)$ indivíduos de sexo indeterminado. Relativamente aos ossos desarticulados, foram identificados 2 crânios de indivíduos do sexo feminino (ossário_1[UE7A-2] e ossário_5[UE50-9]) e um úmero de um indíviduo masculino (UE144-1).

2.3. Paleopatologia: que lesões foram identificadas nos indivíduos inumados no adro da igreja de Sarilhos Grandes?

\section{- Patologia oral}

Do total de 21 indivíduos inumados, 8 (38,1\%) preservaram dentição erupcionada. Se tivermos em conta toda a amostra, foram estudados 219 dentes erupcionados, 95 maxilares $(43,4 \%)$ e 124 mandibulares $(56,6 \%)$, dos quais 212 se encontravam soltos e apenas 7 nos respetivos alvéolos. Desta forma, apenas foi possível estudar a presença de lesões cariogénicas, tártaro e hipoplasias do esmalte.

Dos 8 indivíduos que apresentavam dentes erupcionados, 7 evidenciavam pelo menos uma cárie dentária e o não adulto $\mathrm{n}^{\circ}{ }^{\circ}, \operatorname{com} 4,5$ a 6 anos de idade à morte, era o único que não apresentava qualquer lesão cariogénica (Tabela 1). Do total da amostra analisada, 123 dos 219 dentes (56,2\%) apresentavam pelo menos uma cárie, sendo que a dentição inferior apresenta mais cáries que a superior $(58.1 \%$ vs 53.3\%), mas sem diferença estatística significativa (Pearson $\chi^{2}=0,419 ; d . f=1 ; p=0,517$ ). Se tivermos em conta apenas as lesões cavitadas, 49 dos 219 dentes $(22,4 \%)$ apresentam pelo menos uma cárie, pelo que a maior parte das lesões se encontrava numa fase inicial. Infelizmente, estas frequências não podem ser comparadas com outras populações coevas, uma vez que o número de dentes estudado é pequeno. No entanto, as cáries são das patologias mais fre- quentes nas diferentes épocas históricas e podem ter causas multifatoriais, estando associadas a fatores de risco como a placa dentária, o ambiente ou a genética (Lucas $\mathbb{Z}$ alii, 2010). Um dos factores que pode ter contribuído para o desenvolvimento de cáries, particularmente nos indivíduos em análise, é o fungo da espécie Candida albicans, identificado com microscópio eletrónico de varrimento no tártaro do $\mathrm{I}^{\circ}$ molar superior direito do indivíduo adulto $\mathrm{n}^{\circ}{ }^{17}$, um indivíduo adulto do sexo feminino (Pereira $\mathbb{\&}$ alii, 2017). Este microorganismo pode estar presente na cavidade oral humana como agente patogénico e potenciar a origem de doença periodontal e de cáries (e.g., Falsetta $\mathbb{E}$ alii, 2014).

Quanto ao tártaro, foi identificado em 5 dos 8 (62,5\%) indivíduos com dentes erupcionados, todos adultos (1 masculino, 1 feminino, 3 indeterminados). No total, foi registado tártaro em 25,6\% (56/219) dos dentes, sendo que não há diferenças significativas entre a presença de tártaro na dentição maxilar e mandibular (Pearson $\chi^{2}=1,174 ; d . f=1 ; p=0,279$ ). O tártaro dentário resulta da mineralização dos depósitos de placa, mas a sua quantidade parece estar associada à interação entre fatores genéticos, alimentares (proteínas), fraca higiene dentária, entre outros ainda não completamente compreendidos (Hillson, 2005). No entanto, os valores aqui obtidos devem ser interpretados com precaução devido às alterações tafonómicas bastante evidentes nos dentes e que terão também condicionado as observações em laboratório, muito possivelmente subestimando as frequências em vida.

No que diz respeito às hipoplasias do esmalte, foram registadas na dentição dos indivíduos adultos no 13 e 17 e, se tivermos em conta o conjunto estudado, em 13 do total de 217 (9\%) dentes. As hipoplasias foram identificadas em dentes definitivos e são de tipo linear, as mais comummente encontradas em populações do passado (Towle e Irish, 2020). Apesar de uma maior frequência na dentição maxilar em relação à mandibular, não foram observadas diferenças estatísticas (Pearson $\chi^{2}=3,640 ; d . f=1 ; p=0,056$ ). As hipoplasias do esmalte são interpretadas por bastantes estudos como marcadores de stresse não específico durante o desenvolvimento dentário e podem dar pistas sobre doenças e stresses nutricionais das crianças na comunidade em que se inserem (Towle e Irish, 2020). No entanto, atualmente é reconhecido que algumas destas lesões podem ter outras causas, como trauma ou doenças infeciosas 
coexistentes ou ainda fatores genéticos ou ambientais específicos (Towle e Irish, 2020).

\section{- Os não adultos de Sarilhos Grandes e o stresse nutricional}

Para além da patologia oral, várias foram as lesões ósseas observadas e algumas podem também dar-nos luzes sobre possíveis stresses nutricionais. Neste particular, são os indivíduos não adultos que ganham maior protagonismo. Foi identificada porosidade e formação de osso novo em três ossos temporais desarticulados de lateralidade indefinida (UEo1-9, UE84-7 e UE101-2), todos de indivíduos não adultos, assim como nos ossos temporais (ambos de lado indeterminado) dos indivíduos 12 (35 a 39 semanas de vida) e 18 ( $>40$ semanas e $<1,5$ meses) (Figura 3). As alterações nos temporais UEı12 e no esqueleto 12 enquadram-se nos casos mais típicos das alterações 'hair-on-end' observadas na hipertrofia medular descrita para a hiperostose porótica (Ortner, 2003). Para além disso, no indivíduo 12 foi também identificada formação de osso novo porótico no zigomático direito, maxilar (de lado indeterminado), pars lateralis esquerdo do occipital e (embora menos evidentes) na mandíbula, na escápula (face dorsal e fossa supraespinhosa) e ilium (principalmente na face gluteal) direitos, para além de uma costela bífida ou bifurcada, isto é, com a metade esternal dividida em duas (Figuras 3 e 4). Esta última condição é raramente descrita em paleopatologia e não parece associada às restantes lesões do indivíduo. Estudos clínicos referem que ocorre em cerca de 0,15\%-0,31\% da população, com predileção pelo lado direito da caixa torácica (Kurihara $\&$ alii, 1999), tal como acontece no indivíduo aqui estudado. Numa coleção de 101 tomografias axiais do Centro Hospitalar Universitário de Coimbra e 74 indivíduos da Coleção de Esqueletos Identificados do Século XXI, curada pela Universidade de Coimbra, a costela bífida foi identificada em 1,7\% (3/175) dos indivíduos, todos de sexo masculino (Nogueira, 2013/2014). São normalmente assintomáticas ou com poucas implicações clínicas (Kurihara $\&$ alii, 1999). No feto/recém-nascido no 10 foi ainda registada formação de osso novo na face anterior do osso zigomático direito e, na base dessa órbita, juntamente com porosidade (Figura 3 ).

Particularmente no que diz respeito às lesões do indivíduo 12, diversas doenças (assim como a sua coexistência) podem provocar formação de osso novo e porosidade similar em não-adultos, como é o caso do escorbuto, do raquitismo, da talassemia ou da anemia falciforme (Tabela 2). No entanto, o padrão de distribuição das lesões enquadra-se no descrito na literatura para o escorbuto (e.g., Lewis, 2018). A deficiência de vitamina $C$ será mais evidente em não adultos não amamentados, uma vez que os seus níveis são muito mais baixos no leite de vaca (Lewis, 2018). Neste contexto, a hipovitaminose precisaria de um período de alguns meses de forma a manifestar-se no esqueleto, até porque os seus sintomas são reconhecidos clinicamente apenas entre os $4 \mathrm{e}$ os 10 meses de vida (Lewis, 2018) e o indivíduo em análise terá entre 35 a 39 semanas de gestação, o que parece excluir este diagnóstico. Infelizmente, essas alterações ósseas em recém-nascidos estão ainda pouco estudadas para qualquer das doenças incluídas no diagnóstico diferencial, pelo que, na falta de evidências patognomónicas e, uma vez que o indivíduo é um feto/recém-nascido, o diagnóstico não poderá ser afirmativo. O mesmo acontece para as lesões inespecíficas dos indivíduos 1o e 18 (Figura 3) e restantes ossos desarticulados.

Já a identificação isolada de hiperostose porótica requer um diagnóstico diferencial ainda com maiores reservas. É uma das lesões mais comummente identificadas em restos arqueológicos humanos e que leva ao aumento da porosidade do osso esponjoso no crânio, principalmente em prejuízo da tabula exter$n a$, sendo que, até há pouco tempo, a sua patogénese era quase exclusivamente associada à anemia por deficiência de ferro (e.g., Ortner, 2003). No entanto, o âmbito das condições que podem causar hiperostose porótica é atualmente tido como mais alargado (Brickley, 2018). Walker \& alii (2009) referem que vários estudos hematológicos mostraram que a anemia megaloblástica resultante da deficiência das vitaminas B9 e B12, quer com origem nutricional, quer associada a infeções parasíticas gastrointestinais, estão na base da hiperostose porótica. No primeiro caso, essas deficiências nutricionais estão associadas a dietas com escassez de alimentos de origem animal, praticamente a única fonte de vitamina B12; no segundo caso, correlacionam-se com infeções parasitárias, como as associadas ao Giardia lamblia, Enterobius vermicularis ou Ascaris lumbricoides, que interfere e diminui significativamente a absorção de vitamina B12 (Walker \& alii, 2009). Os mesmo investigadores sugerem que os recém-nascidos adquirem essa deficiência em vitamina B12 das suas mães, nascem com 
reservas que diminuem pelos efeitos sinergéticos que o leite materno, também carente da vitamina, lhes proporciona, acrescido das condições de vida insalubres que muitas vezes resultam em infeções gastrointestinais. Não sabemos se haveria escassez de alimentos de origem animal, particularmente para as progenitoras destes indivíduos, mas as análises paleoparasitológicas realizadas nas amostras de solo recolhidas na zona pélvica de 5 indivíduos adultos $\left(n^{\circ} 8,9,13,17\right.$ e 22) revelaram a presença de parasitas em 4, em dois deles ( $\mathrm{n}-8$ e 22) de Ascaris lumbricoides, o mais comum na Europa e frequentemente associado à falta de condições de higiene e salubridade (Pereira \& alii, 2017; Sianto \& alii, 2018). O indivíduo 22 revelou também a presença de ovos de Oxyoroidea de origem não humana, possivelmente adquirido atráves do consumo de carne de caça, enquanto os indivíduos 9 e 13 manifestaram a presença de ovos do género Trichostrongylus, um parasita de animais de criação como coelhos, porcos, bovinos e ovinos (Pereira \& alii, 2017; Sianto $\&$ alii, 2018). No entanto, é importante referir que são vários os processos patológicos que podem contribuir para este tipo de alterações morfológicas específicas, tais como certos processos inflamatórios do escalpe, alterações decorrentes de lesões no periósteo do exocrânio, hematomas subperiostais com origem traumática ou mesmo a malária (Ortner, 2003; Smith-Guzmán, 2015). A taxa de mortalidade nos períodos Medieval e Moderno, quer entre adultos quer entre não adultos, era alta. Era frequente cada núcleo familiar ter perdido vários filhos na sua infância e calcula-se que um terço das crianças falecesse antes de completar um ano de vida (Marques, 2010; Rodrigues, 2008) Apesar da preocupação existente nos tratados médicos destes períodos, o sistema imunitário infantil via-se frequentemente associado à má alimentação generalizada. No caso de não adultos, o consumo alimentar similar ao dos adultos afectava consideravelmente o desenvolvimento fisiológico. Por sua vez, estes problemas interligavam-se invariavelmente a febres de várias origens e a problemas do foro intestinal, aumentando, desta forma, a taxa de mortalidade (Oliveira, 2015). Mas eram as doenças infecciosas a principal causa de mortalidade. Como já foi defendido, nos séculos XVI e XVII a esperança média de vida à nascença não ultrapassava a barreira dos 25 para os homens e 38 anos para as mulheres (Rodrigues, 2008). O desenvolvimento dos grandes centros urbanos portugueses a partir do séc. XVI, com especial destaque para Lisboa, levou a que a cidade e as suas áreas periféricas - como é o caso de Sarilhos Grandes - se vissem afectadas por surtos endémicos de peste e de outras doenças.

\section{- Outras lesões identificadas}

Cinco fragmentos de ossos do crânio (um frontal e parietais e quatro indeterminados) do mesmo indivíduo apresentam múltiplos osteomas disseminados sem um padrão observável, alguns com o típico aspeto de formação óssea pedunculada, com o pescoço mais estreito que a sua extremidade e que Eshed $\&$ alii (2002) definem como hamartomas (Figura 5). Estas lesões são descritas como tumores benignos de crescimento lento e são mais frequentes a partir da quarta ou quinta década de vida (Eshed \& alii, 2002). Duas mulheres adultas (no 9 e 19) exibem nódulos de Schmorl, na primeira na superfície inferior de uma vértebra torácica e, na segunda, numa torácica e numa lombar. Estes nódulos são depressões encontradas nos corpos vertebrais, normalmente nas vértebras torácicas mais inferiores e nas lombares, possivelmente resultado da tensão biomecânica associada às atividades do quotidiano, mas também do peso corporal, deficiências metabólicas ou da predisposição genética (Plomp, Roberts e Vidarsdóttir, 2012; Burt \& alii, 2013). A dor nas costas é frequentemente referida como um dos sintomas; há, no entanto, estudos que mostram que podem ser assintomáticos (Plomp, Roberts e Vidarsdóttir, 2012).

Foram ainda registados vários exemplos de patologia articular, apesar do pequeno número de epífises preservadas. O indivíduo masculino $\mathrm{n}^{\circ} 22$ possuia osteoartrose no cotovelo e anca. Nos ossos desarticulados, a mandíbula [UE47-10], a vértebra cervical [UE47-11], o fragmento de tíbia [UE50-8], o cuneiforme lateral [UE59-12] e a primeira falange proximal do pé direito [UE7A-23] evidenciam também esse tipo de lesões. A osteoartrose, caraterizada pela deterioração da cartilagem e do osso de uma ou mais articulações, é uma das doença mais frequentes em populações do passado (Burt \& $\mathbb{\&}$ alii,, 2013). Este desgaste progressivo resulta numa distorção da posição articular que causa dor, inchaço e rigidez na articulação do indivíduo vivo (Burt $\&$ alii,, 2013). Tem uma etiopatogénese multifatorial mais associada ao sexo feminino, à idade mais avançada, a ocupações com maior exigência física ou à repetição de movimentos, à genética ou à obesidade (e.g., Weiss e Jurmain, 2007). 
A superfície articular da $\mathrm{I}^{\mathrm{a}}$ falange proximal [UE7A23] do pé direito, para além da osteortrose evidenciada pela eburnação, apresenta perda do contorno ósseo normal na área medial e destruição óssea na zona mais profunda da articulação, assim como entre esta e a zona de perda de contorno normal do osso (Figura 6). Também a $1^{\mathrm{a}}$ falange proximal [UEo1-2] do pé direito possui destruição óssea no centro da superfície articular, com forma bastante irregular e com o osso em torno da lesão aparentemente em diferentes fases de remodelação (Figura 6). Ambos os casos devem incluir a osteocondrite dissecante no diagnóstico diferencial, embora não se enquadrem na descrição típica daquela condição (Aufderheide e Rodríguez-Martin, 2011). A osteonecrose, uma condição circulatória que se carateriza pela morte das células ósseas (Ortner, 2003), deve ser também equacionada. A cabeça de fémur esquerdo [UE131-12] evidencia remodelação óssea bem demarcada e regular (Figura 6), alterações que podem ser também associadas à osteocondrite dissecante ou a uma muito fase inicial de artrite séptica; no entanto, o diagnóstico diferencial é, mais uma vez, bastante difícil, por um lado porque se tratam de ossos desarticulados (não é possível perceber se há simetria nas lesões ou se existiriam noutras articulações) e, por outro, especificamente porque neste último caso são interpretadas alterações ósseas num pequeno fragmento. O trauma é descrito como o fator etiológico mais provável para a osteocondrite dissecante, seja num único episódio ou em sucessivos de microtraumatismo resultante de atividade vigorosa (Ortner, 2003). É mais frequente em indivíduos do sexo masculino e no joelho, embora a anca também seja uma articulação relativamente afetada (Ortner, 2003). A osteoartrose é tida como uma complicação a longo prazo (Ortner, 2003), o que pode estar na base da eburnação observada na falange [UE7A-23].

Finalmente, no indivíduo no 21 foi identificada fusão simétrica e bilateral de duas falanges intermédias e distais do $4^{\circ}$ ou $5^{\circ}$ dedo do pé, podendo ter origem congénita. Um possível diagnóstico será o de sinfalangismo, uma malformação mais comum nas falanges distais do $2^{\circ}$ ao $5^{\circ}$ dedo (Aufderheide e Rodríguez-Martin, 2011).

\section{PERPETIVAS FUTURAS}

O atual programa de investigação plurianual do projeto SAND propõe o estudo sistemático dos ves- tígios osteológicos (humanos e fauna), cerâmicos e demais materiais recuperados nas escavações realizadas em 2008 e a realizar em 2020. Para concretizar estes objetivos, o projeto envolve uma equipa multidisciplinar de História, Arqueologia, Antropologia, Biologia, Química e Paleoparasitologia. A realização de uma nova intervenção bio-arqueológica na necrópole da Igreja de São Jorge e na Ermida de Nossa Senhora da Piedade permitirá aprofundar questões por esclarecer e abrir novas perspetivas de estudo sobre a população de Sarilhos Grandes desde época Medieval.

\section{AGRADECIMENTOS}

Os autores gostariam de agradecer ao Vítor Matos e à Ana Rita Sampaio a ajuda prestada.

\section{REFERÊNCIAS BIBLIOGRÁFICAS}

ALQAHTANI, S. J.; HECTOR, M. P.; LIVERSIDGE, H. M. (2009) - Brief communication: the London Atlas of $\mathrm{Hu}-$ man Tooth Development and Eruption. American Journal of Physical Anthropology, 142, pp. 481-49o.

AUFDERHEIDE, A. C; RODRÍGUEZ-MARTÍN, C. (2011) - The Cambridge encyclopedia of human paleopathology. Cambridge: Cambridge University Press.

BELLO, S. M.; THOMANN, A.; SIGNOLI, M.; DUTOUR, O.; ANDREWS, P. (2006) - Age and sex bias in the reconstruction of past population structures. American Journal of Physical Anthropology, 129, pp. 24-38.

BUIKSTRA, Jane E.; UBELAKER, H. Douglas (1994) Standards for data collection from human skeletal remains. Fayetteville: Arkansas Archaeological Survey Research Series, No. 44 .

BURT, Nicole M.; SEMPLE, Dyan; WATERHOUSE, Kathryn; LOVELL, Nancy C. (2013) - Identification and interpretation of joint disease in Paleopathology and Forensic Anthropology. Springfield: Charles C. Thomas Publisher, Ltd.

CARDOSO, Hugo Filipe Violante (200o) - Dimorfismo sexual na estatura, dimensões e proporções dos ossos longos dos membros: o caso de uma amostra Portuguesa dos séculos XIX-XX. Dissertação de Mestrado em Evolução Humana. Coimbra: Departamento de Antropologia da Univerisdade de Coimbra.

CARNEIRO, Cristiana; CURATE, Francisco; CUNHA, Eugénia (2016) - A method for estimating gestational age of fetal remains based on long bone lengths. International Journal of Legal Medicine, 130, pp. 1333-1341.

CARTER,DavidO.;TIBBETT,Mark(2008)-Cadaverdecomposition and soil: processes. In TIBBETT, Mark e CARTER, 
David O., eds. - Soil analysis in forensic taphonomy. Boca Raton, CRC Press - Taylor and Francis, pp. 29-51.

DIAS, Mário Balseiro Dias (2005) - Visitações e provimentos da Ordem de Sant'Iago em Aldeia Galega de Ribatejo. Volume 1 (1486-1537). Montijo: ed. autor.

DIGANGI, E. A.; BETHARD, J. D.; KIMMERLE, E. H.; KONIGSBERG, L. W. (2009) - A new method for estimating age-at-death from the first rib. American Journal of Physical Anthropology, 138, pp. 164-176.

ESHED, V.; Latimer, B.; GREENWALD, C. M.; JELLEMA, L. M.; ROTHSCHILD, B. M.; Wish-Baratz, S.; HERSHKOVITZ, I. (2002) - Button osteoma: its etiology and pathophysiology. American Journal of Physical Anthropology, 118, pp. 217-230.

FALSETTA, Megan L.; KLEIN, Marlise I.; COLONNE, Punsiri M.; SCOTT-ANNE, Kathleen; GREGOIRE, Stacy; PAI, Chia-Hua, GONZALEZ-BEGNE, Mireya;WATSON, Gene; KRYSAN, Damian J.; BOWEN, William H.; KOOM, Hyun (2014) - Symbiotic relationship between Streptococcus mutans and Candida albicans synergies virulence of plaque biofilms in vivo. Infection and Immunity, 82:5, pp. 1968-1981.

FEREMBACH, D.; SCHWIDETZKY, I.; STLLOUKAL, M. (1980) - Recommendations for age and sex diagnoses of skeletons. Journal of Human Evolution, 9:7, pp. 517-549.

HILLSON, S. (2001) - Recording dental caries in archaeological human remains. International Journal of Osteoarchaeology, 11, pp. 249-289.

HILLSON, S. (2005) - Teeth. Cambridge Manuals in Archaeology. Cambridge: Cambridge University Press.

ISCAN, M. Y.; LOTH, S. R. (1993) - Casts of age phases from the sternal end of the rib for white males and females. Bellevue (CO): France Casting.

KIBBLEWHITE, Mark; TÓTH, Gergely; HERMANN, Tamás (2015) - Predicting the preservation of cultural artefacts and buried materials in soil. Science of the Total Environment, 529, pp. 249-263.

KURIHARA, Yasuyuki; YAKUSHIJI, Yoshiko; MATSUMOTO, Junichi; ISHIKAWA, Tohru; HIRATA, Kazuaki (1999) - The ribs: anatomic and radiologic considerations. Radiographics, 19(1): 105-119.

LEWIS, M. (2012) - Thalassaemia: its diagnosis and interpretation in past skeletal populations. International Journal of Osteoarchaeology, 22, pp. 685-693.

LEWIS, M. (2018) - Paleopathology of children: identification of pathological conditions in the human skeletal remains of non-adults. San Diego: Academic Press.

LUCAS, S.; SEVIN, A.; PASSARIUS, O.; ESCLASSAN, R.; CRUBEZY, E.; GRIMOUD, A. M. (2010) - Study of dental caries and periapical lesions in a Mediaeval population of the southwest France: differences in visual and radiograph- ic inspections. HOMO - Journal of Comparative Human Biology, 61:5, pp. 359-72.

MACLAUGHLIN, S. M. (1990) - Epiphyseal fusion at the sternal end of the clavicle in a Modern Portuguese skeletal sample. Antropologia Portuguesa, 8, pp. 59-68.

MARQUES, A.H. de Oliveira (2010) - A Sociedade Medieval Portuguesa. Aspectos de vida quotidiana. Lisboa: Esfera dos Livros. 6 $6^{\underline{a}}$ ed.

OLIVEIRA, Ana Rodrigues (2015) - O dia-a-dia em Portugal na Idade Média. Lisboa: Esfera dos Livros.

ORTNER, D. J. (2003) - Identification of pathological conditions in human skeletal remains. San Diego: Academic Press.

PEREIRA, Paula Alves; SANTOS, José Costa; GODINHO, Ricardo; GONÇALVES, David (2008) - Relatório final da escavação de emergência da Necrópole do Largo da Igreja (Sarilhos Grandes). Pengest/TFP Planege.

PEREIRA, Paula Alves; SIANTO, Luciana; CHAVES, Sérgio Augusto de Miranda; TEIXEIRA-SANTOS, Isabel; GONÇALVES, D.; SANTOS, Ana Luísa; TOSO, Alice; CALLEJA, Álvaro M. Monge; COUTINHO, António Pereira; ARAÚJO, Ana Cristina; GODINHO, Ricardo Miguel (2017) A necrópole do largo da igreja (Sarilhos Grandes): evidências bioarqueológicas de contato entre Portugal e o Novo Mundo. Sines, História e Património, o Porto e o Mar Actas, pp. 123-141.

PLOMP, K. A.; ROBERTS, C. A.; VIDARSDÓTTIR, U. N. (2012) - Vertebral morphology influences the development of Schmorl's nodes in the lower thoracic vertebrae. American Journal of Physical Anthropology, 149, pp. 572-582.

RODRIGUES, T. F. (coord) (2008) - História da População Portuguesa. Porto: CEPESE \& Edições Afrontamento.

ROGERS, J.; WALDRON, T. (1995) - A field guide to joint disease in Archaeology. Chichester: John Wiley \& Sons.

SCHEUER, L.; BLACK, S. (200o) - Developmental juvenile osteology. San Diego: Academic Press.

SIANTO, Luciana, CHAVES, Sérgio Augusto de Miranda; TEIXEIRA-SANTOS, Isabel; PEREIRA, Paula Alves; GODINHO, Ricardo Miguel; GONÇALVES, David; SANTOS, Ana Luísa (2018) - Evidence of contact between New and Old World: paleoparasitological and food remains study in the Tagus river population of Sarilhos Grandes (Montijo, Portugal). Archaeological and Anthropological Sciences, 10: 75-81.

SILVA, A. M. G. da (1993) - Os restos humanos da gruta artificial de São Pedro do Estoril II: estudo antropológico. Volume I. Relatório de Investigação em Ciências Humanas. Coimbra, Departamento de Antropologia da Universidade de Coimbra.

SILVA, A. M. (1995) - Sex assessments using the calcaneus and talus. Antropologia Portuguesa, 13, pp. 107-119. 
SMITH-GUZMÁN, Nicole E. (2015) - The skeletal manifestations of malaria: an epidemiological approach using documented skeletal collections. American Journal of Physical Anthropology, 158, pp. 624-635.

TOWLE, Ian; IRISH, Joel, D. (2020) - Recording and interpreting enamel hypoplasia in samples from archaeological and palaeoanthropological contexts. Journal of Archaeological Science, 114, pp. 105077.

UBELAKER, D. H. (1974) - Reconstruction of demographic profiles from ossuary skeletal samples: a case study from the tidewater Potomac. Smithsonian Contributions to Anthropology, 18. Washington; Smithsonian Institution Press.

WALKER, Phillip L.; BATHURST, Rhonda R.; RICHMAN, Rebecca; GJERDRUM, Thor; ANDRUSHKO, Valerie A. (2009) - The causes of porotic hyperostosis and cribra orbitalia: a reappraisal of the iron-deficiency-anemia hypothesis. American Journal of Physical Anthropology, 139, pp. 109-125.
WASTERLAIN, R. S. C. N. (200o) - Morphé: análise das proporções entre os membros, dimorfismo sexual e estatura de uma amostra da colecção de esqueletos identificados do Museu Antropológico da Universidade de Coimbra. Dissertação de Mestrado em Evolução Humana. Coimbra, Departamento de Antropologia da Universidade de Coimbra.

WEISS, E.; JURMAIN, R. (2007) - Osteoarthritis revisited: a contemporary review of aetiology. International Journal of Osteoarchaeology, 17, pp. 437-450.

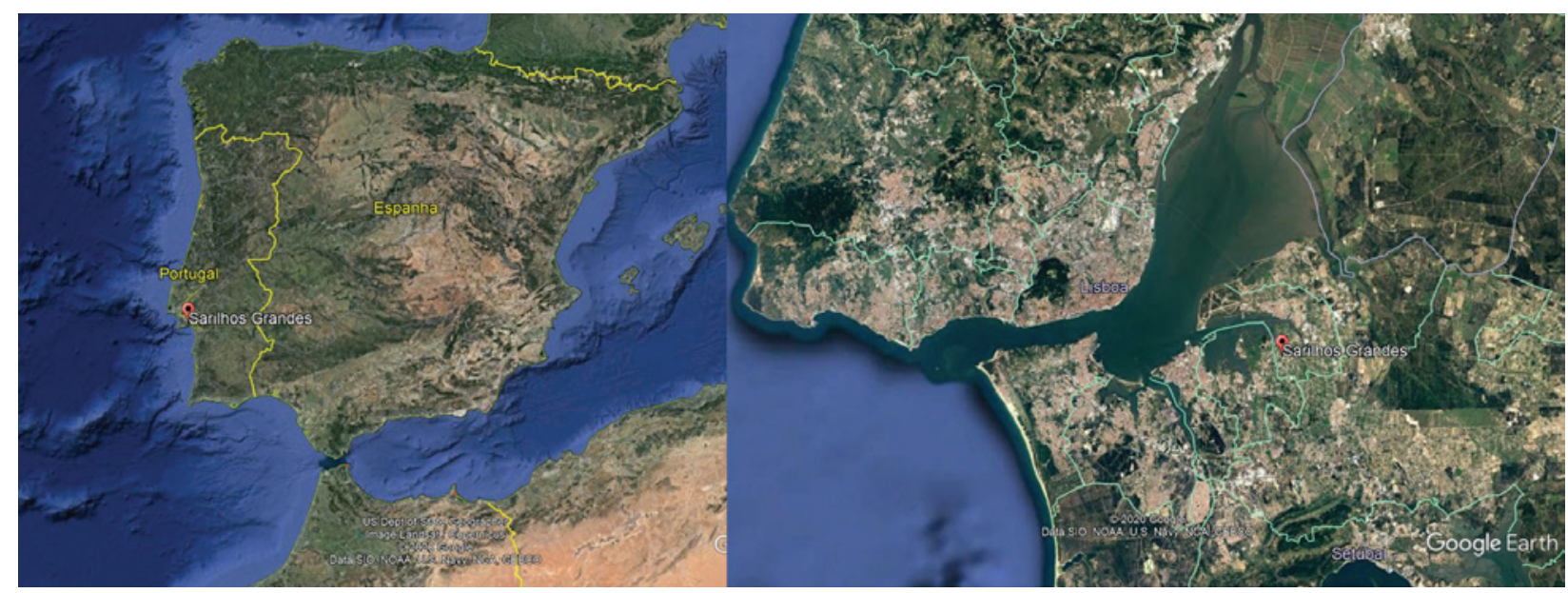

Figura 1 - Localização de Sarilhos Grandes. Mapa adaptado Google Earth. Consulta 22 de junho de 2020.

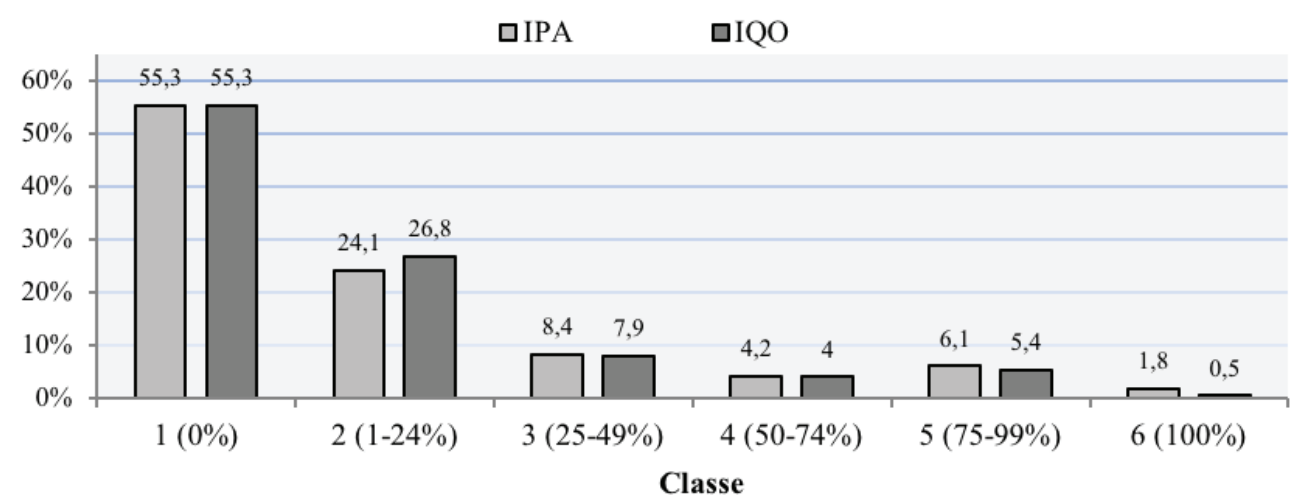

Figura 2 - Índice de Preservação Anatómica (IPA) e Índice de Qualidade Óssea (IQO) por classe de preservação entre os 21 esqueletos. 

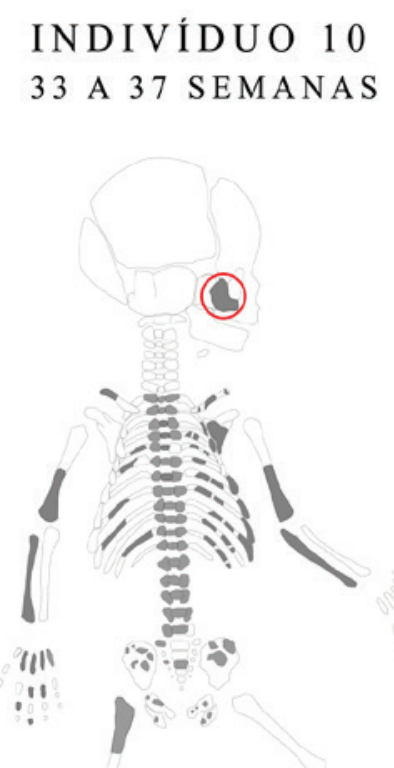

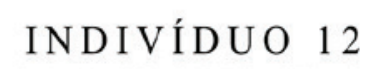

35 A 39 SEMANAS

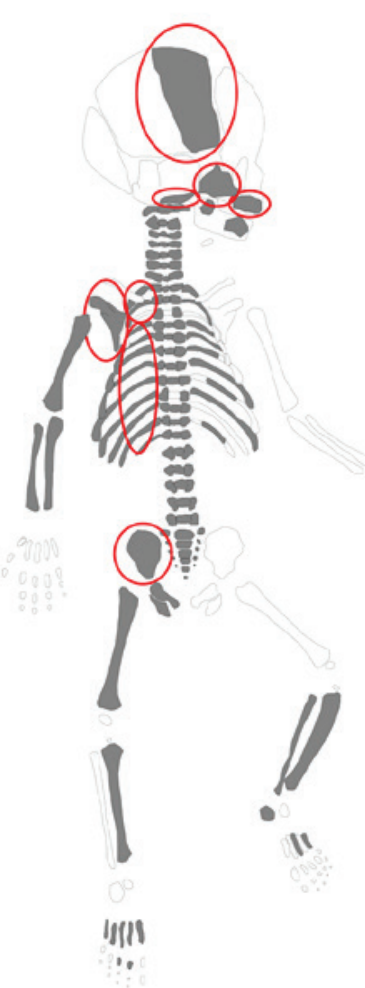

\author{
INDIVÍDUO 18 \\ $>40$ SEMANAS \\ $<1,5$ MESES
}

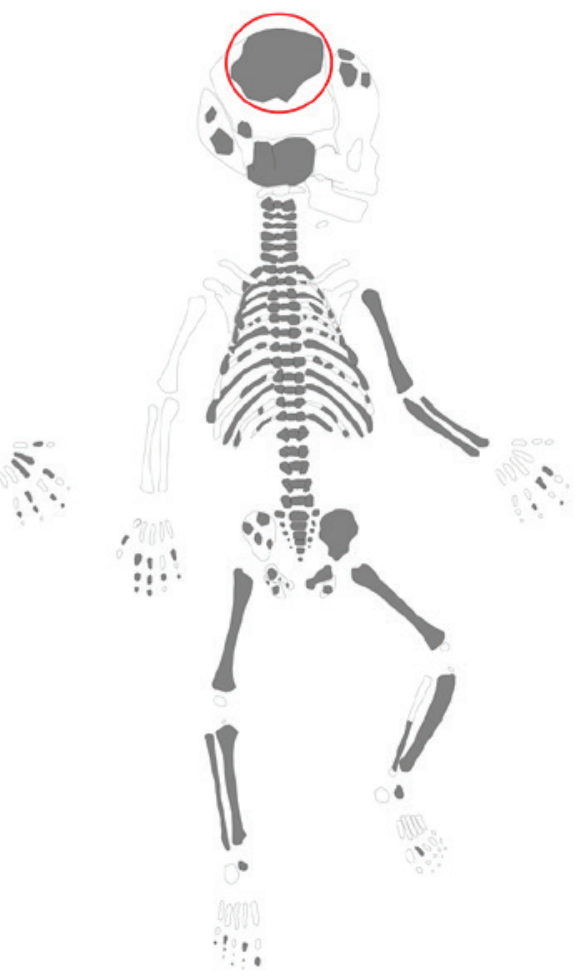

ossos PRESEntes Olesóns

Figura 3 - Ossos e lesões presentes nos indivíduos 10, 12 e 18, os três indivíduos mais novos.

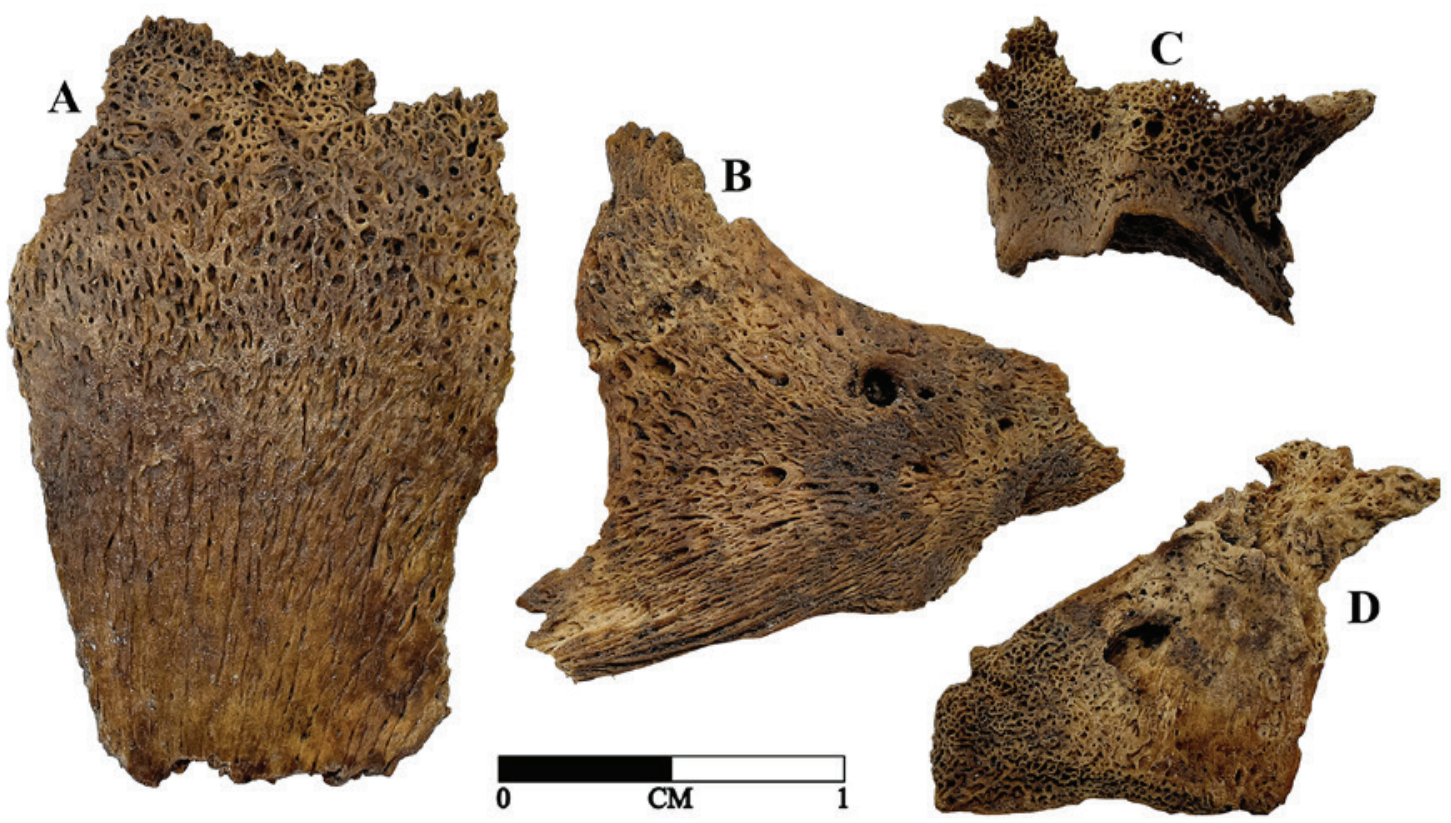

Figura 4 - Ossos do crânio do esqueleto 12 (35 a 39 semanas) com evidências de lesões patológicas: parietal (A) com hiperostose porótica e zigomático direito (B), maxilar (C) e pars lateralis esquerda (D) com formação de osso poroso. 


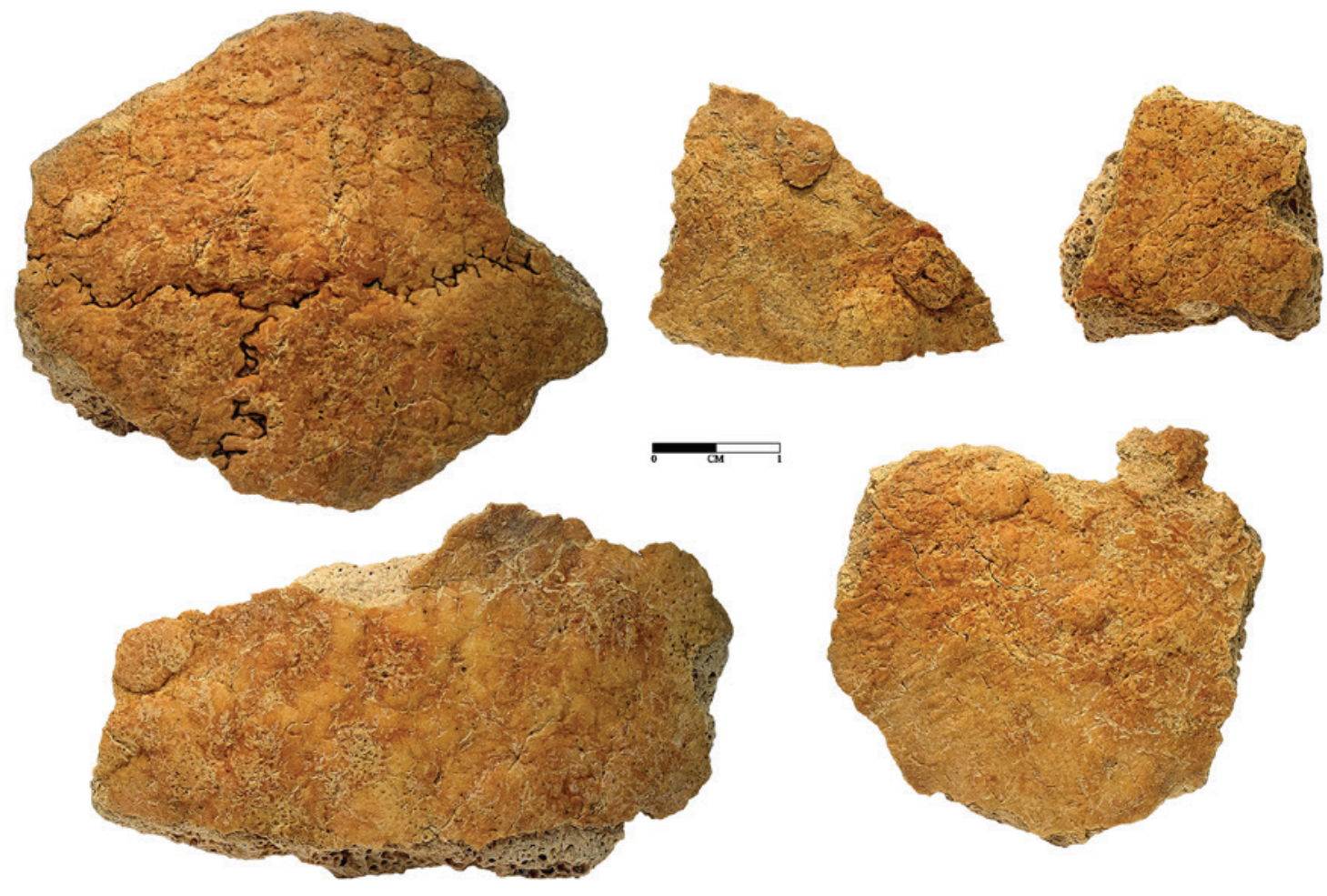

Figura 5 - Fragmentos desarticulados de um crânio de adulto provenientes da [UE18] com osteomas múltiplos disseminados.

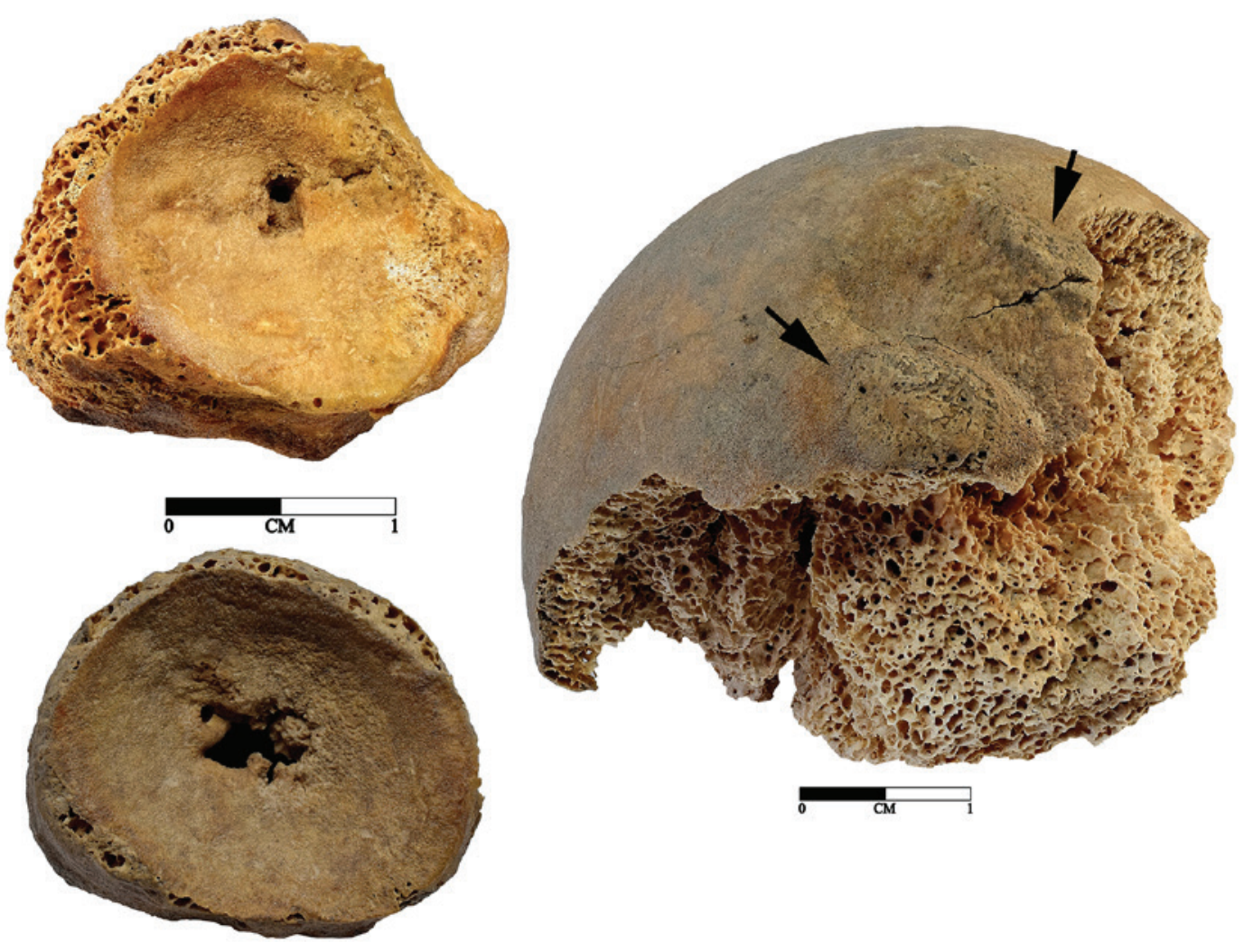

Figura 6 - Ossos desarticulados com lesões provavelmente associadas a osteocondrite dissecante: falanges proximais do pé [UE7A-23] (à esquerda em cima) e UEo1-2 (à esquerda em baixo) e cabeça do fémur [UE131-12] (à direita). A falange [UE7A-23] apresenta ainda eburnação que evidencia a presença de osteoartrose. 


\begin{tabular}{|c|c|c|c|c|c|c|c|c|c|c|c|}
\hline \multirow{2}{*}{ Indivíduo [UE] } & \multirow{2}{*}{$\begin{array}{l}\text { Idade à morte e } \\
\text { sexo biológico }\end{array}$} & \multirow{2}{*}{ Dentição } & \multicolumn{3}{|c|}{ Cáries } & \multicolumn{3}{|c|}{ Tártaro } & \multicolumn{3}{|c|}{$\begin{array}{l}\text { Hipoplasias } \\
\text { do esmalte }\end{array}$} \\
\hline & & & $\mathrm{n}$ & $\mathrm{O}$ & $\%$ & $\mathrm{n}$ & $\mathrm{O}$ & $\%$ & $\mathrm{n}$ & $\mathrm{O}$ & $\%$ \\
\hline \multirow{2}{*}{ № 1 [09] } & \multirow{2}{*}{4,5 a 6 anos } & Superior & 4 & 5 & 80 & $\mathrm{O}$ & 5 & $\mathrm{o}$ & $\mathrm{O}$ & 5 & $\mathrm{o}$ \\
\hline & & Inferior & 1 & 1 & 100 & $\mathrm{o}$ & 1 & $\mathrm{o}$ & $\mathrm{o}$ & 1 & $\mathrm{o}$ \\
\hline \multirow{2}{*}{ № 3 [15] } & \multirow{2}{*}{4,5 a 6 anos } & Superior & $\mathrm{o}$ & 1 & o & $\mathrm{o}$ & 1 & $\mathrm{o}$ & $\mathrm{o}$ & 1 & $\mathrm{o}$ \\
\hline & & Inferior & $\mathrm{o}$ & 1 & $\mathrm{o}$ & $\mathrm{o}$ & 1 & $\mathrm{o}$ & $\mathrm{o}$ & 1 & $\mathrm{o}$ \\
\hline \multirow{2}{*}{ № $6[40]$} & \multirow{2}{*}{ Adulto } & Superior & 4 & 10 & 40 & 1 & 10 & 10 & $\mathrm{o}$ & 10 & $\mathrm{o}$ \\
\hline & & Inferior & 9 & 13 & 69,2 & $\mathrm{o}$ & 13 & $\mathrm{o}$ & $\mathrm{o}$ & 13 & $\mathrm{o}$ \\
\hline \multirow{2}{*}{ № $8[51]$} & \multirow{2}{*}{ Adulto masculino } & Superior & 1 & 6 & 16,7 & 5 & 6 & 83,3 & $\mathrm{O}$ & 6 & $\mathrm{O}$ \\
\hline & & Inferior & 8 & 11 & 72,7 & 4 & 11 & 36,4 & $\mathrm{o}$ & 11 & $\mathrm{o}$ \\
\hline \multirow{2}{*}{ № 13 [77] } & \multirow{2}{*}{ Adulto } & Superior & 10 & 10 & 100 & 4 & 10 & 40 & 4 & 10 & 40 \\
\hline & & Inferior & 7 & 8 & 87,5 & $\mathrm{o}$ & 8 & $\mathrm{o}$ & 2 & 7 & 28,6 \\
\hline \multirow{2}{*}{ № 14 [82] } & \multirow{2}{*}{ Adulto jovem } & Superior & 8 & 16 & 50 & $\mathrm{o}$ & 16 & $\mathrm{o}$ & $\mathrm{o}$ & 16 & $\mathrm{o}$ \\
\hline & & Inferior & 13 & 16 & 81,3 & $\mathrm{o}$ & 16 & $\mathrm{o}$ & $\mathrm{o}$ & 16 & $\mathrm{o}$ \\
\hline \multirow{2}{*}{ № 15 [9o] } & \multirow{2}{*}{ Adulto } & Superior & 9 & 12 & 75 & 5 & 12 & 41,7 & $\mathrm{o}$ & 12 & $\mathrm{o}$ \\
\hline & & Inferior & 5 & 9 & 55,6 & 5 & 9 & 55.6 & $\mathrm{o}$ & 9 & $\mathrm{o}$ \\
\hline \multirow{2}{*}{ № 17 [100] } & \multirow{2}{*}{ Adulto feminino } & Superior & 5 & 6 & 83,3 & 3 & 6 & 50 & 4 & 6 & 66,7 \\
\hline & & Inferior & 2 & 5 & 40 & 3 & 5 & 60 & $\mathrm{O}$ & 5 & $\mathrm{o}$ \\
\hline \multirow{2}{*}{ Dentes desarticulados } & \multirow{2}{*}{-} & Superior & 10 & 29 & 34,5 & 2 & 29 & 6,9 & 1 & 29 & 3,4 \\
\hline & & Inferior & 27 & 60 & 45 & 22 & 60 & 36,7 & 2 & 60 & 3,3 \\
\hline \multicolumn{3}{|c|}{ Total dentição superior } & 51 & 95 & 53,3 & 20 & 95 & 21,1 & 9 & 95 & 9,5 \\
\hline \multicolumn{3}{|c|}{ Total dentição inferior } & 72 & 124 & 58,1 & 34 & 124 & 27,4 & 4 & 122 & 3,3 \\
\hline \multicolumn{3}{|c|}{ Total } & 123 & 219 & 56,2 & 54 & 219 & 24,7 & 13 & 217 & 6 \\
\hline
\end{tabular}

$\mathrm{n}=$ Cáries presentes; $\mathrm{O}=$ Dentes observáveis

Tabela 1 - Resultados referentes às lesões cariogénicas, tártaro e hipoplasias do esmalte do indvíduos com dentição preservada e dos dentes desarticulados.

\begin{tabular}{|c|c|c|c|}
\hline \multicolumn{2}{|c|}{ Doença } & Causa & Alterações ósseas normalmente associadas \\
\hline \multirow[t]{2}{*}{ Metabólica } & Escorbuto & $\begin{array}{l}\text { Deficiência } \\
\text { de vitamina C }\end{array}$ & $\begin{array}{l}\text { Hiperostose porótica craniana, porosidade nas grandes asas do esfenóide, } \\
\text { impressões vasculares ectocranianas, cribra orbitalia e formação de osso } \\
\text { nas órbitas, inflamação das gengivas, formação de osso na fossa supra e } \\
\text { infra espinhosa da escápula, fraturas ou alargamento adjacente à junção } \\
\text { costocondral das costelas, formação de osso e porosidade nas metáfises } \\
\text { dos ossos longos, porosidade nas superfícies interna e externa do ilium } \\
\text { (e possível espessamento). }\end{array}$ \\
\hline & Raquitismo & $\begin{array}{c}\text { Deficiência } \\
\text { de vitamina D }\end{array}$ & $\begin{array}{l}\text { Ramo mandibular deformado, erupção dentária atrasada, fratura, } \\
\text { curvatura anormal e achatamento das costelas, desgaste na extremidade } \\
\text { esternal e porosidade anormal nas costelas, deformação dos ossos longos } \\
\text { inferiores, osteopenia. }\end{array}$ \\
\hline \multirow[b]{2}{*}{$\begin{array}{l}\text { Anemia } \\
\text { genética }\end{array}$} & Talassemia & $\begin{array}{l}\text { Desequilíbrio } \\
\text { na síntese da } \\
\text { hemoglobina }\end{array}$ & $\begin{array}{l}\text { Hiperostose porótica craniana; alterações nos ossos faciais ('fácies de } \\
\text { roedor'); aspeto radiográfico de 'costela dentro de costela' representada } \\
\text { por uma banda de osso radiopaco; osteomas costais; osteopenia e } \\
\text { porosidade generalizadas. }\end{array}$ \\
\hline & $\begin{array}{l}\text { Anemia } \\
\text { falciforme }\end{array}$ & $\begin{array}{l}\text { Produção } \\
\text { anormal de } \\
\text { hemoglobina }\end{array}$ & $\begin{array}{l}\text { Osso cortical da tabula externa mais fino nos parietais devido a progressão } \\
\text { do diploe, que pode acontecer também nos zigomáticos e teto das órbitas, } \\
\text { formação de osso novo, osteomielite e alargamento do osso cortical na tíbia } \\
\text { e fíbula em contraste com o adelgaçamento nas talessemias, epífises podem } \\
\text { tornar-se necróticas (necrose da cabeça do fémur é frequente), dactilite } \\
\text { (aspeto de 'dedo em salsicha'). }\end{array}$ \\
\hline
\end{tabular}

Tabela 2 - Doenças que podem causar alterações similares às verificadas no indivíduo 12 (a partir de Ortner, 2003; Lewis 2012, 2018). 



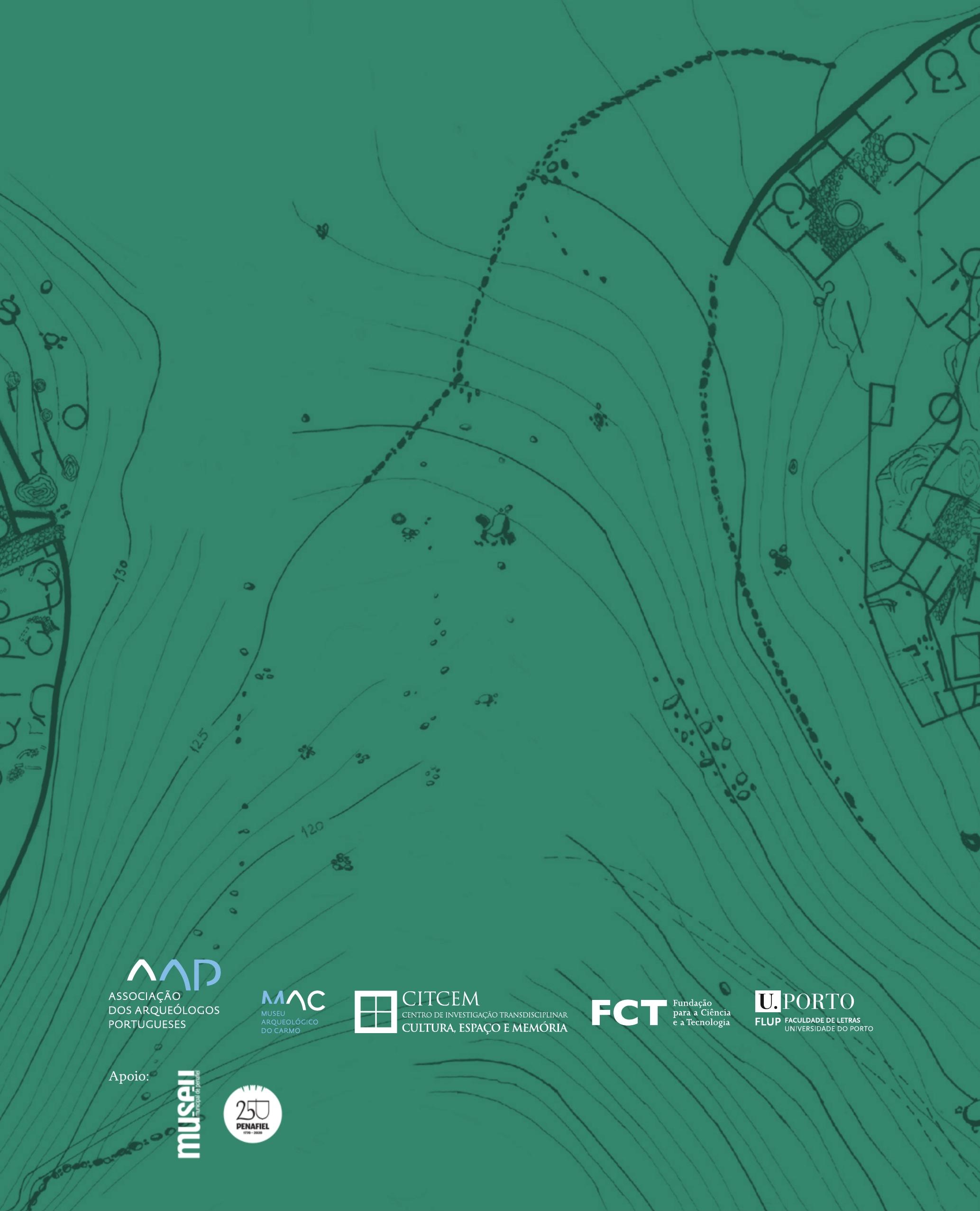

